\title{
Las teorías económicas del desarrollo sostenible
}

\author{
Eguzki Urteaga \\ Universidad del País Vasco \\ Departamento de Sociología 1 \\ Los Apraiz, 2 \\ 01006 Vitoria \\ Tel: 945014260 \\ Fax: 945013308 \\ eguzki.urteaga@ehu.es
}

\begin{abstract}
RESUMEN
Lanzado como un lema hace veinte años, el desarrollo sostenible se ha convertido en uno de los principales retos del siglo XxI. Presentado como la solución a todos los problemas que se plantean a la humanidad, el desarrollo sostenible aparece como un enigma: ¿Cómo es posible aumentar el bienestar de la población mundial, luchar contra las desigualdades sociales y, simultáneamente, salvaguardar la dinámica de la biosfera? ¿Conviene confiar en el capitalismo y la regulación por los precios, crear nuevas normas que enmarquen el capitalismo y, si es el caso, deben estar producidas por actores públicos o privados? La problemática del desarrollo sostenible nos conduce a preguntarnos sobre las nociones de crecimiento, desarrollo, bienestar así como sobre la pertinencia del descrecimiento, por lo menos en las regiones más prosperas del planeta.
\end{abstract}

Palabras clave: desarrollo sostenible, medioambiente, crecimiento, planeta, teorías.

Clasificación JEL: A1, B1, B2, N3, N7, Q2, Q7 


\begin{abstract}
Launched as a motto twenty years ago, sustainable development has become one of the major challenges of the twenty-first century. Presented as the solution to all the problems that appear to the humanity, sustainable development appears as an enigma: how it is possible to increase the well-being of the world population, to fight against the social inequalities and, simultaneously, to preserve the dynamics of the biosphere? Should we trust on capitalism and regulation of prices, create new rules that fit the capitalism and, if it is the case, they must be produced by public or private actors? The issue of sustainable development leads us to ask us about the notions of growth, development, welfare and on the relevancy of the decrease, at least in the most prosperous regions of the planet.
\end{abstract}

Key words: sustainable development - environment - growth - planet - theories JEL: A1, B1, B2, N3, N7, Q2, Q7

\title{
1. INTRODUCCIÓN
}

La noción de desarrollo sostenible es un elemento omnipresente en los discursos y acciones de los actores implicados en las cuestiones medioambientales y de desarrollo. La abundante literatura interesada por este tema aumenta constantemente y ofrece un amplio panorama: se habla de sostenibilidad social, de sostenibilidad financiera, de empleos duraderos o de ciudades duraderas. Existe, en esta profusión, un efecto de moda y su carácter indefinido contribuye a su éxito. La confusión proviene en parte de la dificultad de encontrar una traducción satisfactoria del inglés sustainable que designa la acción de apoyar, sostener, mantener y nutrir. La controversia en torno al sentido de la noción de desarrollo sostenible proviene también de la ambigüedad del concepto de desarrollo. No se trata de considerar este término como unívoco y las definiciones, criterios y traducciones concretas de este fenómeno como si fuesen objeto de un consenso.

Es frecuente presentar el desarrollo sostenible como la solución a los problemas a los que se enfrentan las sociedades contemporáneas. El informe Brundtland ha contribuido al éxito de esta noción. Pero la unanimidad que la rodeo la convierte en sospechosa porque muestra una voluntad de ocultar los conflictos, de infravalorar las divergencias y de aniquilar los argumentos contradictorios ${ }^{1}$. El desarrollo sostenible ofrece

1 P. Lascoumes, «Les ambigüités des politiques de développement durable», in Michaud. Y., La nature et les risques. Paris, Odile Jacob, 2002. 
una plasticidad ampliamente utilizada por los actores, ya que cada uno quiere convencer a los demás de la pertinencia de su punto de vista, mientras que nos encontramos a menudo ante un reciclaje de propósitos, objetivos y métodos de trabajo elaborados con otros fines y en circunstancias diferentes. Se trata de invertir este razonamiento. El desarrollo sostenible, más que una solución, es un problema. Esta noción no se ha estabilizado y es el objeto de múltiples definiciones e interpretaciones, moviliza a una pluralidad de referencias y de enfoques, los indicadores elegidos son cuestionados, los objetivos a alcanzar son problemáticos así como los medios disponibles. Debatir del desarrollo sostenible nos obliga a dar cuenta de esta complejidad.

La definición del desarrollo sostenible más citada es la que figura en el informe Brundtland: «Un desarrollo que responde a las necesidades del presente sin comprometer la capacidad de las generaciones futuras de responder a las suyas». Se trata de «una cuestión normativa sin norma $»^{2}$. ¿Cómo se puede aumentar el bienestar de la población mundial, luchar contra las desigualdades sociales y, al mismo tiempo, salvaguardar la dinámica de la biosfera? ¿Cuáles pueden ser los objetivos, las modalidades, las políticas y los instrumentos para alcanzar dicho objetivo? Las opiniones divergen en la materia y existe una fuerte competencia para dar un contenido normativo al desarrollo sostenible. No obstante, las ciencias sociales y económicas han construido en parte como unos discursos normativos sobre la manera según la cual deben organizarse las sociedades. Ello explica por qué dichas ciencias se han movilizado tanto en la problemática del desarrollo sostenible, cuya emergencia está vinculada a la identificación de anomalías en los niveles social y medioambiental.

\section{LAS TEORÍAS DEL CRECIMIENTO DURADERO}

La búsqueda de las condiciones económicas, sociales y medioambientales de la acumulación de la riqueza a largo plazo no es nueva. Para los clásicos, la mejora de las condiciones de vida pasa por la creación de una plusvalía económica que debe ser reinvertida con el fin de aumentar la cantidad de capital disponible y la riqueza producida. No obstante, a largo plazo, estos teóricos vislumbran ciertos límites al crecimiento. Así, influenciada por la teoría demográfica de Malthus (1803), la tesis del «estado estacionario» ha prevalecido durante un largo período. En los años 1930, como

2 J. Theys. «A la recherché du développement durable: un détour par les indicateurs», in Jollivet. M., Développement durable, de l'utopie au concept. Paris, Economica, 2001, p.273. 
consecuencia de las evoluciones económicas que conoce Europa, las tesis «estagnacionistas» se extienden todavía más. Es únicamente a partir de la segunda mitad del siglo xx cuando, en el contexto de los «Treinta Gloriosos» (1945-1975), las ideas de crecimiento y de desarrollo toman la forma y la importancia que revisten hoy en día. Desde este período, se observa una gran continuidad en las propuestas de la teoría económica dominante. El modelo de Solow constituye el elemento central de la respuesta neoclásica a la problemática del desarrollo sostenible. Otros trabajos vienen completar esta teoría intentando mostrar que, bajo ciertas condiciones que se refieren a la innovación técnica, la continuidad del crecimiento económico coincide con el desarrollo y la protección del medioambiente.

\subsection{La teoría neoclásica del crecimiento}

El debate teórico sobre el crecimiento, que se desarrolla durante los Treinta Gloriosos, está estructurado en parte en torno a una oposición entre economistas keynesianos y neoclásicos. Keynes, que ha conocido la gran depresión de los años 1930 y el auge tanto del nazismo como del fascismo, con sus repercusiones económicas y sociales, está convencido de que, por su dinámica propia, el sistema capitalista está condenado a la crisis. Enfrentadas a la incertidumbre radical que caracteriza el largo plazo, las empresas privadas privilegian las inversiones que son rentables a corto plazo. Lo que provoca una inversión global y unas ofertas de empleo insuficientes que sumergen el capitalismo en una situación de desempleo crónico. Por lo cual, el Estado debe intervenir para apoyar a la inversión y al empleo. A la espera del advenimiento de valores alternativos en las sociedades de abundancia, Keynes preconiza una política de grandes obras y un reparto más equitativo de la riqueza para asegurar el crecimiento económico. Si se conceden ingresos adicionales a las clases populares, que tienen una mayor propensión al consumo, se incrementará la demanda, lo que incitará los empresarios a invertir y a contratar. Por lo tanto, es importante conciliar la equidad social y la eficacidad económica para que la dinámica del capitalismo prosiga.

Keynesianos como Harrod y Domar, que elaboran los primeros modelos de crecimiento en los años 1940, ponen de manifiesto la inestabilidad de la dinámica capitalista proveniente de las dificultades de coordinación a los que se enfrentan los que toman las decisiones de ahorrar y de invertir. Asimismo, insisten sobre la necesidad de una intervención del Estado para paliar en parte a los efectos de los problemas de crecimiento a largo plazo. Por su parte, a partir de la mitad de los años 1950, los neoclásicos dan una respuesta positiva. Replantean la pregunta, centrando la atención en el mantenimiento de una economía en equilibrio. Este 
modelo debe ser comprendido como una parábola y una historia simplificada: la economía es representada como una función de producción macroeconómica que produce un solo bien gracias a la ayuda de dos factores de producción: el capital y el trabajo. Este último, que depende del crecimiento demográfico, está considerado como exógeno y en aumento constante. No sucede lo mismo con el capital que depende de la inversión. Se trata de la única decisión que debe tomar el planificador. En cada momento, debe determinar qué cantidad de bien producido no será consumido, sabiendo que el ahorro está automáticamente invertido para producir capital. Solow muestra así que, sea cual sea el capital inicial, esta economía tiende hacia un régimen casi estacionario en donde todas las variables del modelo (producción, consumo e inversión) crecen según una tasa constante. Entre los regimenes concebibles, se encuentra el que autoriza un elevado nivel de consumo por persona, aplicando la regla según la cual la elección de la tasa de ahorro óptimo es tal que conduce a una formación de capital cuya productividad marginal es similar a la tasa de crecimiento de la economía. Así, se ha demostrado la posibilidad de un crecimiento equilibrado a largo plazo, gracias a una acumulación del capital.

\subsubsection{El reconocimiento del capital natural}

Concebido en los años 1950, este modelo no toma en consideración los problemas planteados por la naturaleza. No obstante, con un artículo titulado The economics of ressources on the ressources of economics, Solow (1974) ha sido uno de los primeros neoclásicos en reaccionar ante el cuestionamiento del crecimiento por el informe Meadows. El reto de la sostenibilidad aparece en filigrana en este texto dedicado al problema del agotamiento de los recursos naturales, a través de una representación del crecimiento que se sitúa en la continuidad de lo que prevalece en los años 1950. Sucede lo mismo cuando, veinte años más tarde, la problemática de la sostenibilidad es planteada explícitamente por Solow (1992). Se traduce por el «no-decrecimiento» en la época del bienestar individual, lo que puede medirse por el nivel de utilidad, de renta o de consumo. Para que el bienestar económico de las futuras generaciones sea, como mínimo, similar al de las generaciones actuales, conviene, gracias a una tasa de ahorro suficientemente elevado, que el stock de capital disponible sigua intacto. Está compuesto por equipamientos, conocimientos y competencias así como por recursos extraídos de la naturaleza.

Se considera esta última como una forma particular de capital. En el artículo de Solow, los recursos minerales son identificados como tales. En el texto publicado en 
1992, analiza también la calidad del medioambiente como un capital que pierde su valor con la contaminación que deteriora el medioambiente y que se aprecia a través de la inversión en las actividades de descontaminación. A partir de los años 1990, el concepto de capital natural, que aparece en filigrana en los escritos económicos de los años 1970, forma parte del razonamiento de los neoclásicos en materia de crecimiento económico. No obstante, retienen la hipótesis de la posible sustitución entre las distintas formas de capital: una cantidad superior de equipamientos, de conocimientos y de competencias debe tomar el relevo de unas cantidades inferiores de capital natural, para asegurar el mantenimiento en el tiempo de las capacidades de producción y de satisfacción del bienestar de los individuos. Para Solow ${ }^{3}$, la actitud conservadora no puede generalizarse porque es imposible ceder el planeta en el estado en el cual lo hemos encontrado. Los recursos naturales ordinarios, que no permiten producir bienes y servicios, deben poder ser sustituidos. Se produce así un intercambio en el tiempo: la generación presente consume servicios medioambientales y recursos naturales, pero lega, en contrapartida, a las generaciones futuras más capacidades de producción.

Varias hipótesis son necesarias para asentar esta tesis. La primera se refiere al progreso técnico que debe ofrecer un conjunto de «técnicas de socorro» que permitan la sustitución entre las diferentes formas de capital. Los neoclásicos avanzan la hipótesis de la existencia de blackstop technologies, es decir de soluciones técnicas ante el agotamiento de los recursos naturales y la destrucción de los servicios medioambientales. El del precio de estos recursos, a medida que se enrarece, convierte a estas técnicas de socorro en rentables. La segunda hipótesis es relativa a la definición del régimen de inversión particular que debe permitir financiar estos relevos: la regla de Hartwick (1977) estipula que las rentas procuradas por la explotación de los recursos naturales agotables deben ser reinvertidas en el capital técnico a través de un sistema de tasación o un fondo de inversión específico. Una tercera hipótesis concierne a las preferencias de las generaciones futuras que deberán acomodarse a la sustitución realizada entre los diferentes tipos de bienes y servicios. Por último, se pone el énfasis sobre un cierto número de informaciones necesarias para que los agentes puedan tomar sus decisiones en contextos de incertidumbre. Solow insiste, por ejemplo, en la necesidad de una intervención razonable de las administraciones públicas en el ámbito de las innovaciones técnicas y en el de la producción de información en materia de reserva de recursos naturales.

${ }^{3}$ R. M. Solow, «An almost practical step toward sustainability», en Oates. W.E., The REF Reader in Environmental and Resource Management. Washington D.C., Resources for the Future, 1992, p.268. 
Los trabajos empíricos de Barnett (1979), que prolongan los análisis que había llevado a cabo precedentemente con Morse sobre la economía de Estados Unidos durante el período 1890-1960, parecen corroborar estas propuestas: la sustitución de los recursos naturales que se enrarecen por aquellos que son abundantes se realiza perfectamente; la acumulación de conocimientos, de competencias y de habilidades adquiridas en los ámbitos concernidos han jugado un papel importante; incluso la disponibilidad de un cierto número de recursos se ha incrementado; la equidad intergeneracional, medida en términos de disponibilidad de recursos y de productividad, también ha sido respetada. En esta versión de la sostenibilidad, las coacciones que pesan sobre la dinámica del sistema económico no son tan importantes: la reafirmación de la prioridad del crecimiento, la confianza en el progreso técnico, la oscilación del precio, el rol de las instituciones públicas en lo que respeta a algunos ámbitos considerados como estratégicos para el futuro de las diferentes formas de capital. Esta importancia de los poderes públicos en una estrategia de crecimiento sostenible es subrayada aún más por los teóricos del crecimiento endógeno.

\subsubsection{El crecimiento endógeno duradero}

A partir de la mitad de los años 1980, los neoclásicos desarrollan una nueva generación de modelos que, supuestamente, dan cuenta de la divergencia de trayectoria que se observa entre la dinámica de los países desarrollados y la de los países emergentes, lo que contradice las presunciones del modelo de Solow según las cuales, sean cuales sean las dotaciones iniciales de capital y de trabajo, las economías convergen a largo plazo. Se critica también este modelo por el carácter ad hoc de las hipótesis de Solow que se refieren al progreso técnico. Por lo tanto, se trata de explicar por los determinantes del modelo, la producción de innovaciones sobre los cuales se fundamenta la dinámica económica, lo que conduce a elaborar unos modelos del «crecimiento endógeno». Estos se presentan como un conjunto de variantes del modelo de Solow en las cuales la dinámica de la acumulación del capital alimenta el crecimiento de la economía a largo plazo gracias a la innovación técnica, los fenómenos de aprendizaje y la inversión en el capital humano. Si estas nuevas precisiones conciernen a las técnicas, que tienen un impacto sobre el medioambiente, se habla de «crecimiento endógeno duradero» ${ }^{4}$.

${ }^{4}$ Chevé. M., Ragot. L., «La croissance endogène durable», en Schubert. K., Zagamé. P., L'environnement, une nouvelle dimension de l'analyse économique. Paris, Vuibert, 1998. 
Las interpretaciones posteriores dan lugar a importantes desarrollos gracias a unos razonamientos acrobáticos realizados a partir de agentes representativos o de empresas dotadas de funciones de producción idénticas ${ }^{5}$. Los teóricos insisten en la presencia de externalidades positivas que constituyen los fenómenos de bienes colectivos y de rendimientos crecientes que se derivan del aumento de las habilidades, de la producción de conocimientos y de las innovaciones técnicas. Efectivamente, estos elementos son difícilmente controlables de manera privada y producen efectos acumulativos en lo que se refiere a la producción de riqueza ${ }^{6}$. No obstante, estas externalidades positivas, que benefician a todos, no son generalmente tomadas en consideración por los agentes económicos individuales, lo que provoca ineficiencias en la concesión de los recursos y la necesidad de una intervención del Estado para intentar solucionar este problema. Así, se relanza el debate sobre las políticas públicas a llevar a cabo, especialmente en lo referente a las inversiones en formación y en I+D. Queda por aclarar si estos elementos van necesariamente en el sentido de un menor impacto sobre el medioambiente.

\subsection{Un crecimiento necesario y suficiente}

La idea avanzada desde los años 1970 por ciertos neoclásicos, según la cual el crecimiento continuo va en el sentido de la protección del medioambiente, no ha cesado de fortalecerse. En su respuesta a las propuestas del informe Meadows, Beckerman ${ }^{7}$ se muestra optimista en cuanto a la capacidad de las economías modernas de gestionar la problemática medioambiental. Cita el caso de la contaminación al dióxido de azufre en Estados Unidos cuyo nivel disminuye en numerosos Estados, mientras que el crecimiento del país continúa. Barnett ${ }^{8}$, que en los años 1960 había mostrado su preocupación acerca del aumento de la contaminación, llega a conclusiones similares. Con el transcurso del tiempo, esta propuesta se generaliza y se dirige también a los países

5 Guellec. D., Ralle. P., Les Nouvelles Théories de la croissance. Paris, La Découverte, 1995, p.3.

${ }^{6}$ Foray. D., L'économie de la connaissance. Paris, La Découverte, 2000, p.63.

7 Beckerman. W., «Economists, scientists, and environmental catastrophe», Oxford Economic Papers, vol.24, n³, 1972, p.336.

8 Barnett. H.J., «Scarcity and growth revisited», in Kerry Smith. V., Scarcity and Growth Reconsidered. Baltimore, John Hopkins University Press, 1979, p.187. 
pobres: «A pesar de que el crecimiento económico conduce habitualmente al deterioro del medioambiente en los primeros tiempos, al final, la mejor manera para la mayoría de los países de tener un medioambiente decente es de enriquecerse» ${ }^{9}$. No obstante, el debate en torno a este tipo de argumentos ha cambiado desde la publicación de los artículos de Grossman y Kruger $(1993,1995)$ que desean darle una base empírica. Estos autores han intentado establecer una correlación entre el crecimiento económico y las evoluciones medioambientales, acercando, para algunos países, la renta per capita y las medidas de contaminación del aire y del agua. Según estos resultados, las emisiones contaminantes aumentan con el incremento de la renta per capita, antes de decrecer.

En lo que se refiere a la contaminación por $\mathrm{CO} 2$, el punto de inflexión interviene con una renta media situada entre 4000 y 5000 dólares. A menudo, es más elevada para los demás contaminantes y se sitúa en torno a 8000 dólares per capita. La explicación dada por Grossman y Krueger es que, inicialmente, la pequeña producción industrial genera pocas emisiones contaminantes, antes de que el desarrollo mal controlado de la industrialización provoque un incremento de las emisiones. Los recursos financieros generados por el aumento de la riqueza, el peso creciente de los servicios y los cambios en las preferencias de los individuos permiten reducir las emisiones contaminantes. Así, el efecto de escala, generalmente subrayado por los defensores del medioambiente, que pretende que la contaminación aumenta con el volumen de la producción, está ampliamente compensado por efectos contrarios. Por lo cual, no solamente el aumento de la renta generada por el crecimiento permite, a través de un efecto de perecuación, reducir las desigualdades sociales, sino que además contribuye a modificar de manera virtuosa las relaciones entre crecimiento y medioambiente. Esta tesis contradice el propósito que convierte el crecimiento en el principal responsable del deterioro del medioambiente.

\subsubsection{El desarrollo sostenible como última etapa del crecimiento}

Grossman y Krueger exploran «la relación existente entre el nivel de desarrollo de un país y sus residuos contaminantes», mientras que Selden y Song ${ }^{10}$ hablan de una nueva etapa en materia de desarrollo. En realidad, en estos análisis, se encuentra

9 Beckerman. W., «Economic growth and the environment: Whose growth? Whose environment?» World Development, vol. 20, n 4 , 1992, p.482.

10 Selden. T.M., Song. D., «Environmental quality and development: is there a Kuznets curve for air pollution emissions?» Journal of Environmental Economics and Management, 1994, p.147. 
en filigrana la tesis defendida por Rostow que considera que el desarrollo económico interviene a partir de una cierta fase de la historia de las sociedades humanas. Para él, todas las sociedades pasan por una de las siguientes cinco fases: la sociedad tradicional, las condiciones previas al arranque, el arranque, el progreso hacia la madurez y la era del consumo de masas. Según este esquema, después de haber conocido un auge, las sociedades conocen un crecimiento duradero auto-alimentado que se convierte en el «Funcionamiento normal de la economía». Esta etapa del crecimiento se caracteriza por una modificación de la estructura económica bajo el impulso del progreso técnico y de su difusión en nuevos sectores de actividad. Unas nuevas industrias toman el relevo de las antiguas y proporcionan al capital nuevas posibilidades de inversión. Esta «teoría dinámica de la producción» se parece parcialmente a las explicaciones ofrecidas para dar cuenta de la curva de Kuznets.

Se puede ir más allá en esta aproximación. Al inicio de los años 1960, a pesar de gozar de unos Estados de bienestar, los países desarrollados no tienen nada claro qué actitud deben adoptar. «Se puede elegir entre los niños y el aburrimiento, la extensión de las fronteras interiores del ser humano, la conquista espacial y los placeres simples o, quizás, la destrucción» ${ }^{11}$. Estos propósitos están marcados por un contexto de incertidumbre dominado por la guerra fría. Con el transcurso del tiempo, otras preocupaciones aparecen. Cuando Rostow se interesa por «las posibilidades de supervivencia de la economía mundial» al horizonte 2000, reconoce que las cuestiones del agotamiento de los recursos naturales y de la contaminación pesan sobre el ritmo de acumulación del capital y el crecimiento de las economías. La humanidad se enfrenta a problemas tan espinosos como el agotamiento de los hidrocarburos, la gestión de los residuos nucleares o el cambio climático. No obstante, Rostow ${ }^{12}$ piensa que la aparición de estos problemas «no señala un desastre para la civilización industrial. Podemos controlarla si trabajamos en ello, y este control formará la base de una reanudación de un crecimiento sostenible». Basándose en la evolución de algunas contaminaciones atmosféricas en Estados Unidos, que se han reducido entre los años 1970 y 1974, Rostow concluye que: «manifiestamente, la nación ha tomado una orientación saludable».

Refiriéndose a algunos capítulos del informe de la CMED, que insisten en la disminución de la pobreza como condición previa para un desarrollo más respetuoso del medioambiente, esta propuesta optimista vinculada a la existencia de una curva de

11 Rostow. W.W., Les étapes de la croissance économique. Paris, Seuil, 1963, p.236.

12 Rostow. W.W., L'ultimatum de l'an 2000. Chances de survie de l'économie mondiale. Paris, Econmica, 1981, p.20. 
Kuznets medioambiental ha sido aprobada rápidamente por las instancias internacionales. El Banco Mundial y el PNUE han integrado este argumento en sus informes publicados desde 1992. O'Connor (2002) se refiere también a ello en sus trabajos realizados en el seno de la OCDE. El problema estriba en que este tipo de relación no puede ser generalizado. Los estudios de este tipo, que se han multiplicado a lo largo de estos últimos años ${ }^{13}$, no conducen a un reconocimiento unánime de esta relación. Harbaugh (2002), utilizando nuevos datos, llega a conclusiones diferentes. Sus resultados difieren igualmente cuando recurren a otras especificaciones econométricas. Por lo tanto, la relación entre crecimiento y medioambiente está marcada por la incertidumbre. Arrow ${ }^{14}$ y su equipo ponen de manifiesto que la relación en U invertida vale únicamente para los contaminantes que tienen impactos locales y a corto plazo. Existen contaminantes para los cuales es imposible establecer semejante correlación: las emisiones de gas carbónico y la producción de basura doméstica crecen con la renta per capita. Hay que añadir que semejante relación, cuando existe, no es necesariamente espontánea.

\subsubsection{Intercambios internacionales y protección del medioambiente}

Los trabajos de Grossman y Krueger (1993) son también los primeros en analizar las relaciones entre el comercio internacional y el desarrollo sostenible. A través de unos estudios econométricos realizados en 1991, durante los trabajos preparatorios a la ratificación del Acuerdo de librecambio norte americano (ALENA), estos autores han intentado mostrar que el auge del comercio internacional coincide igualmente con la protección del medioambiente. El argumento principal es que el desarrollo del comercio internacional, vía el juego de las ventajas comparativas, aporta un aumento de la renta de los países que participan en los intercambios internacionales, lo que les permite incrementar las cantidades dedicadas a la protección del medioambiente. Un segundo elemento positivo, conocido como efecto de composición, es que la liberalización de los intercambios va conducir Méjico a especializarse en las producciones que tienen un menor impacto medioambiental: «parece ser que las actividades agrícolas y aquellas que son intensivas requieren menos recursos energéticos y generan menos residuos por unidad producida que los sectores de carácter más capitalista y que utilizan más

${ }^{13}$ Cole. M.A., «Environmental optimists, environmental pessimists and the real state of the world», The Economic Journal, vol.113, 2003.

14 Arrow. K., et al, « Economic growth, carrying capacity, and the environment», Science, vol.268, 1995, p.520. 
capital humano» ${ }^{15}$. Simultáneamente, siempre en virtud de la especialización de los espacios productivos, puede producirse un movimiento de actividades económicas más contaminantes en dirección de Estados Unidos y Canadá, porque estos países se han dotado de reglamentaciones medioambientales mucho más coactivas que Méjico. En fin de cuentas, el deterioro local del medioambiente que conoce America del Norte está compensado por una mejora global del medioambiente. Según un tercer argumento, el comercio internacional favorece las transferencias de tecnologías no contaminantes a través de las inversiones directas hacia el extranjero. Más allá del ejemplo de ALENA, Grossman y Krueger piensan que las conclusiones a las que conducen deben poder generalizarse. Por lo tanto, el comercio de bienes y servicios y los flujos internacionales de capitales van en el sentido de una mejor protección del medioambiente y de un desarrollo sostenible.

Los trabajos relativos a los vínculos entre el comercio internacional y el medioambiente se han multiplicado desde hace algunos años. Copeland y Taylor (2004) confirman la existencia de un efecto técnico y de un efecto de composición, sin olvidar que estos varían en función de los países. Hacen un llamamiento a realizar más trabajos empíricos para explicitar esta relación virtuosa entre el crecimiento de la renta y la mejora de la calidad medioambiental, considerando de manera más detenida el papel desempeñado en la materia por las políticas medioambientales. Asimismo, la influencia de estas últimas sobre el comercio y las inversiones internacionales debe ser mejor valorada.

Aunque no haya sido demostrada empíricamente, la tesis del «comercio dulce» medioambiental es retomada por las instituciones internacionales. La conferencia de Río se ha ubicado en la continuidad de las propuestas realizadas por el GATT, que se ha convertido en la Organización Mundial del Comercio (OMC) en enero de 1995. El grupo de trabajo sobre el comercio y el medioambiente, creado en el seno de esta institución un año antes de la conferencia de Estocolmo, ha sido reactivado para preparar una contribución a la conferencia de Río. Ha dado sus frutos, puesto que uno de los primeros objetivos de la Agenda 21 es la liberalización del comercio. El paradigma de Río convierte el comercio internacional en la solución al desarrollo sostenible, aunque esté a favor de una regulación de dicho comercio. La referencia a este último, que figura en el preámbulo del texto fundador de la OMC, tiene cierta tendencia a desaparecer

15 Grossman. G.M., Krueger. A.B., « Environmental impacts of a north-american freee trade agreement », in Garber. P.M., The Mexico-US Free Trade Agreement. Cambridge, The MIT Press, 1993, p.48. 
de las perspectivas de futuro que dibuja esta institución hoy en día. A pesar de conocer dificultades para definir las normas que rigen algunos recursos particulares, no se cuestiona la liberalización de los intercambios como objetivo general.

\subsection{LA CONFIANZA EN LA REGULACIÓN POR LOS PRECIOS}

Para los neoclásicos, los precios son esenciales en sus recomendaciones normativas ya que permiten, por lo menos en la configuración de un mercado perfecto, un reparto óptimo de los recursos, especialmente gracias a la sustitución entre diversas técnicas y recursos. El problema es que numerosos objetos medioambientales, que se trate de recursos naturales o de contaminaciones, no tienen precio y no son el objeto de un intercambio mercante. Para que entren en los cálculos de los actores públicos y privados, es imprescindible dotarlos de las características de los bienes económicos, concediéndoles un precio y unos derechos de propiedad.

\subsubsection{La internalización de las externalidades}

La teoría neoclásica representa la sociedad como un mundo en el cual las decisiones de los individuos se refieren a bienes cuya lista está dada una vez por todas. En realidad, conviene realizar una distinción entre dos tipos de bienes: los bienes económicos y aquellos que no lo son. Los primeros son bienes raros y apropiados que se intercambian sobre la base de una relación mercante, mientras que los segundos son bienes abundantes y libres, que se encuentran a la disposición de todos. Para los neoclásicos, si la realidad obedece a esta distinción, no hay ningún problema de reparto de los recursos en una situación de competencia perfecta. En este sentido, la existencia de problemas medioambientales resulta de unas interferencias. Los objetos medioambientales se están convirtiendo en bienes raros, mientras que se consideraban hasta entonces como bienes libres y disponibles en cantidades ilimitadas, lo que los excluía del razonamiento económico. No obstante, a pesar de ser cada vez más escasos, los objetos naturales no presentan todavía todas las características de los bienes económicos, lo que impide que las relaciones mercantes juegan plenamente su papel regulador. Estas carencias del mercado conducen a un mal reparto de los recursos que se traduce por la contaminación y el agotamiento de los recursos naturales.

El concepto central utilizado para analizar una situación de desfallecimiento del mercado es el de la externalidad, teniendo en cuenta que el concepto de bien público, 
al que se recurre para analizar los problemas medioambientales, es considerado como un caso de externalidad. Una externalidad se define como una relación entre agentes económicos, que influye positiva o negativamente en el bienestar, sin que esté mediatizada por los precios. Esta externalidad, cuyo ejemplo paradigmático es el humo de las fábricas que contamina su entorno, impide que los agentes integren en sus cálculos económicos los beneficios y los costes que le son vinculados. Los bienes colectivos, por su parte, tienen un aspecto no exclusivo, ya que es difícil controlar el acceso y, por lo tanto, excluir los agentes económicos de su usufructo. Por lo tanto, estos últimos no revelan sus preferencias a propósito de estos bienes porque tienen la seguridad de poder sacar provecho de ello sin pagar el precio correspondiente. Se trata del comportamiento del «pasajero clandestino». En este caso, la externalidad se deriva de un fallo de los derechos de propiedad.

\subsubsection{La extensión del ámbito de la regulación mercante}

La solución preconizada por los neoclásicos para responder a estos desfallecimientos del mercado consiste en integrar en la esfera mercante a los elementos medioambientales que no están plenamente integrados. Lo que supone modificar el marco institucional en el cual los actores económicos toman sus decisiones para que tenga las características de un marco mercante. Se procede a una internalización des las externalidades creando mercados o casi-mercados allá donde no existían, estableciendo señales-precios enviados a los agentes económicos o concediendo derechos de propiedad intercambiables sobre los recursos naturales. Es preciso subrayar que dar un precio a algo no equivale necesariamente a conferirle el estatus de mercancía. Pero, en la práctica, bajo la acción de las instancias reguladoras, la referencia a un universo mercante acaba generalmente por imponerse a las políticas medioambientales.

Bien es cierto que la teoría económica tiene tendencia a aprehender lo no-mercante con las categorías de lo mercante ${ }^{16}$. Una primera modalidad de internalización de las externalidades consiste en hacer intervenir las administraciones públicas para que, tal un perito-tasador, envíen una señal-precio a los actores económicos bajo la forma de un impuesto que corresponde al daño inflingido al medioambiente. Es el principio del

16 Barthélemy. D., Nieddu. M., Vivien. F-D., « Externalités ou production de patrimoines? Les enseignements des travaux récents sur l'agriculture et l'environnement », Géographie, Economie et Société, vol. 6, n³, 2004. 
contaminador-pagador ensalzado por la OCDE desde el inicio de los años 1970 y que conduce a la fiscalidad medioambiental. Otra posible solución institucional, en materia de internalización de las externalidades, es la que consiste en imaginar intercambios de derechos o de licencias sobre el uso de los recursos y de los entornos naturales. Esta idea se traduce por unas concepciones del mercado muy diferentes, aunque postulen la emergencia de los precios y la eficacia de la competencia.

Una primera variante preconizada por los economistas de la escuela de los derechos de propiedad $^{17}$, que han dado un nuevo impulso a las conclusiones de Hardin (1968), se inspira del teorema de Coase. Si no hay costes de transacción, si los derechos de propiedad sobre los recursos están claramente especificados, perfectamente exclusivos y transferibles, su intercambio permite al conjunto de los costes y beneficios de las actividades económicas ser internalizados, de modo que la búsqueda del interés individual no entre en conflicto con la búsqueda del interés general. Por lo tanto, el papel del Estado consiste en definir correctamente estos derechos de propiedad sobre el medioambiente y dejar hacer los individuos que saben mejor que nadie donde se encuentra su interés y obran, de este modo, al bienestar de toda la comunidad. A partir de estas consideraciones, algunos economistas libertarios ${ }^{18}$ defienden una privatización completa del medioambiente. Otra variante del mercado, que corresponde al mercado de la competencia perfecta, es ofrecida por Montgomerry (1972) y su demostración de la existencia de un equilibrio en un mercado que autoriza la contaminación, lo que permite a las industrias concernidas respetar los umbrales de calidad medioambiental al menor coste.

\subsubsection{La evaluación económica del medioambiente}

Las diversas modalidades de regulación se fundamentan, en un momento determinado, en un análisis coste-ventaja que pretende poner en la balanza los costes y los beneficios esperados de las decisiones y de las políticas puestas en marcha. Para ello,

17 Alchian. A.A., Demsetz. H., «The prosperity right paradigm», Journal of Economic History, vol.33, $\mathrm{n}^{\circ} 1,1973$.

${ }^{18}$ Smith. F.L., «La protection de l'environnement par la privatisation écologique: un paradigme pour la réforme environnementale », in Falque. M., Massenet. M., Droits et propriété et environnement. Paris, Dalloz, 1997. 
diferentes categorías de valor son retenidas por la economía neoclásica del medioambiente. Se pueden poner de manifiesto respondiendo a tres preguntas:

1. ¿Un valor para qué? Dos respuestas son posibles: un valor para las utilizaciones u otro valor para la ausencia de utilizaciones. Los usos pueden ser directos o indirectos. Los primeros agrupan a los beneficios procurados a los individuos por el consumo del medioambiente con el fin de comer y de cuidarse. Los segundos conciernen el valor ecológico de los elementos naturales, es decir su papel funcional, tanto en lo que se refiere a la evolución de las especies como en lo que respeta a la dinámica de los ecosistemas, que aseguran indirectamente la elaboración de une serie de servicios medioambientales a las sociedades humanas. Los valores de no uso están vinculados a los valores de existencia del medioambiente. En este sentido, las personas pueden reconocer un valor a unos elementos que no utilizan porque la preservación de la naturaleza les procura una satisfacción moral.

2. ¿Un valor para cuándo? Los valores de uso están considerados inicialmente como valores presentes, aunque los individuos puedan querer reservarse una utilización del medioambiente para más tarde. Se habla entonces de «valor de opción» porque se reserva hoy una opción para mañana. Si se tiene en cuenta que, el destrozo del medioambiente una vez evitado, el tiempo generará nuevos conocimientos en lo que se refiere a su valor, se habla entonces de «valor de casiopción». Existe una tensión en el valor del tiempo entre la depreciación del futuro como consecuencia del alejamiento del horizonte temporal y la abundancia de información que aporta el tiempo con la acumulación del conocimiento.

3. ¿Un valor para quién? En este caso también, varias respuestas son posibles. La primera es un valor para el individuo concernido que recubre las diferentes categorías citadas. Se puede igualmente integrar un valor para las demás personas: el individuo considerado puede desear que los beneficios aportados por el medioambiente beneficien también a los demás o a las siguientes generaciones.

En teoría, el valor económico total del medioambiente ${ }^{19}$ está calculado haciendo la suma de los diferentes valores. Para medirlo, los teóricos neoclásicos han intentado

19 Pearce. D.W., Turner. R.K., Economics of Natural Resources and the Environment. London, Harvester Wheatsheaf, 1990, p.120. 
aproximarse lo más posible a situaciones que figuran un intercambio mercante. Se considera que los individuos actúan como consumidores, cuyas decisiones son tomadas de manera racional, maximizando su utilidad, bajo la presión del presupuesto. Los métodos de evaluación han tratado de medir el consentimiento de los individuos a pagar para beneficiarse de la mejora de la calidad del medioambiente o evitar su deterioro.

\section{DE LA ECONOMÍA ECOLÓGICA A LA ECOLOGÍA INDUSTRIAL}

A lo largo de la historia del pensamiento económico, han existido tradiciones analíticas críticas que han puesto de manifiesto los daños ecológicos ocasionados por el capitalismo ${ }^{20}$. La historia de la cuestión natural está marcada por une serie de problemas planteados por une «economía predadora» cuestionada tanto por los liberales como por los socialistas: la cuestión forestal, muy presente en el siglo XVIII, precede la cuestión del carbón a la que se interesa Jevons durante el siglo XIX. Después de desaparecer tras las consecuencias económicas y sociales de la crisis de 1929 y las dos guerras mundiales, la idea de una economía destructiva vuelve con cierta fuerza a partir del final de los años 1960. Numerosos economistas se preocupan por las consecuencias medioambientales de los Treinta Gloriosos (1945-1975). Asimismo, toman en consideración la especificidad de estos fenómenos, que son irreducibles a la lógica mercante, con el objetivo de articular los fundamentos económicos y medioambientales y crear así una economía ecológica. A pesar de que la creación de una nueva disciplina que integre los conocimientos de la economía y de la ecología sigua siendo un mero proyecto, puede desembocar sobre dos grandes opciones políticas. La primera consiste en crear instituciones públicas capaces de imponer límites a la explotación de la naturaleza y la segunda se expresa con fuerza dentro de la corriente de la ecología industrial.

\subsection{La economía ecológica}

La economía ecológica es una corriente, relativamente variada, cuyo objeto consiste en reflexionar sobre las condiciones de una posible evolución compartida entre los ecosistemas y los sistemas económicos. Si algunos autores toman en consideración las

${ }^{20}$ Martinez-Alier. J., «Some issues in agrarian and ecological economics, in memory of Georgescu-Roegan », Ecological Economics, vol.22, p.225-238. 
dimensiones ecológicas de los recursos naturales, otros insisten más sobre las cuestiones institucionales planteadas por su regulación.

\subsubsection{Una distinción entre crecimiento y desarrollo}

Una cierta concepción económica asocia casi mecánicamente el crecimiento y el desarrollo, hasta el punto de confundirlos. Por el contrario, numerosos economistas, que se sitúan en la continuidad de Schumpeter, tratan de distinguirlos. El crecimiento corresponde a un incremento cuantitativo de bienes y de servicios disponibles, medidos en términos monetarios y físicos. El desarrollo, por su parte, traduce el amejoramiento cualitativo de las condiciones de vida. La definición propuesta por Maréchal (2003) puede considerarse como precursora del desarrollo sostenible: «El desarrollo es la combinación de los cambios mentales y sociales de una población que le permiten hacer crecer, acumulativamente y duraderamente, su producto real global». Si los objetivos difieren, no están necesariamente vinculados, puesto que el crecimiento no tiene porque ser sinónimo de desarrollo. Por lo tanto, las relaciones entre ambos son complejas y originan controversias y la aparición de la noción de desarrollo sostenible no ha hecho sino relanzar el debate.

Así, si Beckerman ${ }^{21}$ recusa cualquier interés de la expresión desarrollo sostenible, porque considera que no aporta nada nuevo al análisis, Daly ${ }^{22}$ y los partidarios de la economía ecológica denuncian el sinsentido de la idea de crecimiento sostenible, que es contradictoria en los términos, y privilegian el análisis del desarrollo sostenible como objeto central de la economía ecológica ${ }^{23}$. Más allá de las distintas maneras de traducir este objetivo, todos estos autores comparten la idea que el medioambiente constituye, de ahora en adelante, el factor que limita el desarrollo económico, mientras que, durante un largo período, ha sido el capital. Hasta hoy en día, esto ha tenido como consecuencia centrar el cálculo económico en las condiciones de reproducción del ca-

${ }^{21}$ Beckerman. W., «Sustainable development: is it a useful concept?» Environmental Values, vol.3, p.191-209.

${ }^{22}$ Daly. H.E., Beyond Growth. The Economics of Sustainable Development. Boston, Beacon Press, 1996.

${ }^{23}$ Costanza. R., Ecological Economics: the Science and Management of Sustainability. New York, Columbia University Press, 1991. 
pital, que no se corresponden con las que aseguran la reproducción de los recursos naturales y humanos.

\subsubsection{Las dimensiones biofísicas de la actividad económica}

Los economistas ecológicos utilizan la termodinámica para elaborar un análisis crítico de la producción de la riqueza, ya que, en la mayoría de los casos, la teoría neoclásica de la producción no refleja ninguna realidad biofísica. La lógica de construcción de esta función de producción se fundamenta en las propiedades de las funciones matemáticas utilizadas y no sobre su capacidad a representar la realidad. En el mejor de los casos, se puede ver una regla de reparto de las rentas entre las diferentes categorías sociales ${ }^{24}$. Reactivando una tradición de pensamiento antiguo, GeorgescuRoegan (1971), que es uno de los pioneros de la economía matemática, ha intentado confrontar los principios de la teoría económica estándar a los de la termodinámica que constituye, según él, una mezcla entre la física y la economía. Este ejercicio lo ha conducido a fustigar la representación analítica neoclásica que muestra un movimiento perpetuo y pone de manifiesto el proceso de producción, en el sentido de una actividad de transformación del mundo.

La termodinámica es precisamente la ciencia física que se interesa por los procesos de transformación desde el punto de vista energético. El primer principio de la termodinámica estipula que la cantidad de energía se conserva y el segundo avanza que se produce un deterioro de la energía cuando se pone en marcha un proceso de transformación energético. La energía reviste entonces una forma cada vez menos disponible y utilizable por los individuos. Para no caer en el «mito energético», Georgescu-Roegan ${ }^{25}$ insiste en la necesidad de extender estas propiedades a la materia, hasta el punto de designar la entropía material como la cuarta ley de la termodinámica. Para retomar uno de estos ejemplos, las partículas de goma dejadas sobre el asfalto por los neumáticos de los automóviles no han desaparecido sino que se han convertido en inutilizables. La recuperación y la reutilización de esta materia dispersa en la naturaleza exigen un tiempo indefinido y una cantidad considerable de energía. Por lo cual, no es suficiente tener

${ }^{24}$ Robinson. J., «Kalecki et Keynes», in Contributions à l'économie contemporaine. Paris, Economica, 1984.

${ }^{25}$ Georgescu-Roegan. N., «L'énergie et les mythes économiques», Revue d'économie politique, vol.88, $\mathrm{n}^{\mathrm{o}} 3,1975, \mathrm{p} .89$. 
una dotación energética para poder producir bienes y servicios. La actividad económica se fundamenta en la explotación de dos fuentes de «baja entropía» que son los recursos materiales y energéticos gracias a los cuales produce bienes y servicios así como elementos de alta entropía bajo la forma de residuos. Los problemas de agotamiento de los recursos naturales y de contaminación encuentran su origen en el carácter antrópico del proceso económico. Pero, la ley de entropía no nos informa sobre la velocidad y la manera según la cual este deterioro energético y material adviene. La actividad humana se encuentra precisamente en esta indeterminación.

\subsubsection{Una necesaria complementariedad}

En esta óptica, la rareza contra la cual lucha la actividad económica se enraíza en las fuentes de baja entropía material y energética. Se trata, según los economistas ecológicos, de una rareza absoluta, que se asocia al nombre de Malthus. Esta concepción se repercute en el análisis de las condiciones de crecimiento económico. Fabricado con materia y energía, el capital técnico necesita también materia y energía para funcionar. Por lo cual, no es imaginable que el capital técnico sustituya completamente al capital natural. Ponen el énfasis en la idea de una complementariedad entre el capital natural y los demás factores de producción que operan en los procesos de producción porque se basan ellos mismos en recursos iniciales de baja entropía. En este marco analítico, el objetivo de la sostenibilidad se define como el no-decrecimiento en el tiempo del stock de capital natural ${ }^{26}$ que permite producir un flujo constante de riquezas, bajo la forma de bienes y de servicios económicos y de servicios medioambientales, tales como las capacidades de depuración o de reciclaje ofrecidas por los sistemas naturales. Aunque el optimismo de los economistas ecológicos hacia la técnica sea moderado, deben tener en cuenta las posibilidades parciales de sustitución que aparecerán a través de un progreso en la eficacidad de la transformación de los flujos materiales y energéticos que entran en las actividades humanas ${ }^{27}$. Es la razón por la cual algunos autores prefieren razonar sobre el mantenimiento en el tiempo de un stock de «capital natural crítico» que debe ser entendido como unos elementos ofrecidos por la naturaleza que son nece-

26 Pearce. D.W., Turner. R.K., Economics of Natural Resources and the Environment. London, Harvester Wheatssheaf, 1990, p.48.

27 Faucheux. S., O'Connor. M., « Un concept contreversé : le capital naturel », Cahier $d u$ C3ED, nº99-01, 1999. 
sarios a las nuevas generaciones. Esta coacción es denominada a veces de «condición de fuerte sostenibilidad».

\subsubsection{Los modelos bio-económicos}

Sin descuidar una acción sobre los precios, la opción instrumental privilegiada por los economistas ecológicos para alcanzar semejante objetivo consiste en establecer unos límites cuantitativos a los recursos explotados y a los rechazos realizados en la naturaleza. De este modo, expresan su escepticismo acerca del análisis neoclásico en términos de internalización de las externalidades. El concepto de externalidad sobrentiende que las situaciones que caracterizan son anormales, mientras que la lógica misma de la actividad económica es de transformar la naturaleza y de suscitar interdependencias entre los actores. Otro motivo de duda proviene del hecho que el procedimiento de internalización de las externalidades se refiere a prejuicios, es decir a contaminaciones que tienen un impacto sobre las funciones objetivas de los agentes económicos. La toma en consideración de los daños ocasionados al medioambiente puede intervenir demasiado tarde puesto que los comerciantes apenas empiezan a percibir una disminución de su bienestar, mientras que algunos umbrales ecológicos han sido superados.

Rompiendo con la idea que consiste a integrar en la esfera económica lo que, en un inicio, le era exterior (las condiciones ecológicas), a la imagen del esquema de las tres esferas de Passet ${ }^{28}$, conciben la economía como un subsistema de un sistema global, constituido por el conjunto de las actividades humanas. Este, forma parte de un sistema más amplio formado por la biosfera. En este caso, el problema estriba en crear relaciones de inserción entre los diferentes sistemas: inserción de lo económico en las actividades sociales, sabiendo que ellas mismas deben integrarse en la biosfera. Los modelos a los que se refieren explícitamente los economistas ecológicos ${ }^{29}$ para definir los límites ecológicos a la actividad humana son los de la economía forestal o de la pesca, teniendo en cuenta que las primeras han sido elaboradas a partir del siglo XVIII, mientras que las segundas han conocido su auge a partir de los años 1960. En estos mo-

28 Passet. R., L'économique et le vivant. Paris, Payot, 1979, p.11.

29 Costanza. R., Daly. H.E., « Natural capital and sustainable development », Conservation biology, vol.6, nº1, 1992. 
delos bio-económicos, el recurso biológico está considerado como un tipo de capital natural cuya gestión conviene optimizar a largo plazo.

Uno de los objetivos a alcanzar es el del rendimiento sostenible máximo, es decir la cantidad máxima de recursos susceptibles de ser explotada en cada período sin poner en peligro su capacidad de regeneración. Otro interés de estos ámbitos de actividad consiste en el hecho de que, muy pronto, han estado obligados a reflexionar sobre las instituciones de regulación susceptibles de responder a las características específicas de estos recursos: libre acceso y tiempo de reproducción que supera ampliamente el horizonte del cálculo económico habitual. El problema es que los resultados de estos modelos se consiguen en un marco estático, con una hipótesis de perfecto conocimiento del stock de recursos disponibles, lo que se produce en pocas ocasiones en la realidad.

A partir de los años 1980, la reflexión sobre la gestión de los recursos naturales empieza a tomar una nueva configuración con el auge de la ecología global y el reconocimiento de los problemas globales de medioambiente. La lucha contra las contaminaciones y la gestión de los recursos naturales deben, desde entonces, considerarse a escala planetaria. A pesar de la gran adquisición de conocimientos en materia de medioambiente, hay que reconocer que la ciencia de la biosfera está en sus inicios. Ante la ausencia de indicadores fiables, es difícil dar un contenido operativo a una bio-economía global. Por lo cual, se trata de definir el tamaño óptimo de la actividad humana sobre el planeta.

En realidad, privilegiar un enfoque tan global y monolítico no representa ningún interés. Efectivamente, el capital natural no es un conjunto homogéneo puesto que está constituido por un conjunto de recursos y de entornos que difieren los unos de los otros por sus características ecológicas, los juegos de actores y, en su caso, los elementos de regulación existentes. Por lo tanto, conviene definir unas reglas particulares para los diferentes tipos de capital natural ${ }^{30}$. Estos principios deben entenderse como reglas mínimas de prudencia: 1) las tasas de extracción de los recursos naturales renovables deben ser iguales a sus tasas de regeneración, 2) las tasas de emisión de residuos deben ser iguales a las capacidades de asimilación y de reciclaje de los entornos en los cuales están rechazados, 3) la explotación de los recursos naturales no renovables debe producirse a un ritmo igual al de su sustitución por los recursos naturales renovables. Estas propuestas recogen ciertas ideas formuladas en su tiempo por los economistas conser-

30 Pearce. D.w., Turner. R.K., Economics of Natural Resources and the Environment. London, Harvester Wheatssheaf, 1990, p.43. 
vadores norte-americanos. Daly ${ }^{31}$ se refiere, por ejemplo, a los trabajos de Ise (1925). Preocupado por el agotamiento de los recursos energéticos y forestales, este preconiza relevar los precios por las administraciones públicas a través de impuestos con el fin de influir sobre la demanda de estos recursos y de cubrir su coste de reproducción, en el caso de los recursos renovables, y su coste de sustitución por otros recursos, en el caso de los recursos no renovables. Otros conservadores recomiendan instaurar un sistema de permiso para la explotación de los recursos naturales.

\subsubsection{La definición de unas normas medioambientales}

En esta misma óptica institucional, Daly propone, desde hace treinta años, establecer diferentes instancias para regular la población mundial, la desigualdad de riquezas y la gestión de recursos naturales. Estas propuestas se parecen a las recomendaciones realizadas por Dales (1968) relativas a la instauración de un sistema de cuotas transferibles para regular la contaminación de los grandes lagos canadienses. En este caso, las administraciones públicas determinan inicialmente una cantidad global de contaminantes que es preciso no sobrepasar y, posteriormente, bajo la forma de permisos con fecha de caducidad, entre los actores económicos concernidos, tienen el derecho de intercambiarlos bajo ciertas condiciones. Como la población y las actividades económicas aumentan, si la oferta de permiso es estable, los precios aumentan; lo que incita los empresarios a poner en marcha unas técnicas de descontaminación. Dates observa que semejante mecanismo es un instrumento administrativo que tiene poco que ver con un mercado. Se trata de un proceso de planificación al que se asocia un sistema de intercambio de cuotas que permiten a las empresas adaptarse lo mejor posible a esta política. Las administraciones públicas no establecen derechos equivalentes a un derecho de propiedad sobre la tierra pero fijan una autorización provisional de rechazar contaminantes. Actúan como un corredor y un regulador: los poderes públicos registran todas las transacciones y, si lo desean, actúan sobre los precios de los permisos, comprando los derechos no expirados o vendiendo los derechos dejados en reserva. La autoridad pública tiene el derecho de evaluar de nuevo el importe global de la contaminación autorizada al final de cada período de validez de los derechos.

31 Daly. H.E., «Entropy, growth, and the political economy of scarcity», in Kerry Smith. V., Scarcity and Growth Reconsidered. Baltimore, John Hopkins Press, 1979, p.97. 
Otros partidarios de la economía ecológica ${ }^{32}$ retoman el concepto de «normas mínimas de salvaguardia» para los sistemas ecológicos que deben ser objeto de una negociación entre las diferentes partes implicadas. En todos los casos, se trata de instaurar una «gestión normativa bajo coacción», es decir determinar unos límites a la explotación de los recursos naturales, definir las condiciones de reparto de esta coacción en el seno de la sociedad que sean las más equitativas posibles y precisar las instituciones que permitirán a los actores económicos tomar unas decisiones óptimas. En realidad, este enfoque se enfrenta a las características socio-epistemológicas en las cuales se desarrollan las negociaciones que tratan de definir las coacciones.

\subsubsection{Convenios medioambientales}

Los problemas ambientales se caracterizan por unas situaciones en «universos controvertidos» ${ }^{33}$ que hacen difícil definir unas normas de gestión. La incertidumbre reina a todos los niveles del peritaje y de la toma de decisión. Si se dispone de un conocimiento científico suficiente sobre la importancia de los retos que plantea, persisten interrogaciones fundamentales con respecto a las causas, consecuencias y responsabilidades que conviene invocar a su propósito. Más aún, los daños medioambientales no están directamente percibidos por los agentes y ciertos intereses concernidos están ausentes de las negociaciones o disponen de portavoces contradictorios. Algunos actores económicos, que aprehenden la problemática según una estrategia de «riesgo inverso ${ }^{34}$, intentan utilizar la ciencia de manera estratégica para incidir sobre la negociación. Así, un juego de actores donde se mezclan controversias científicas, intereses industriales, lógicas políticas y efectos mediáticos, construye la problemática.

Puesto que es imposible tener un perfecto conocimiento del problema planteado para poner en marcha una política susceptible de solucionarlo, el proceso de decisión toma poco a poco su autonomía con respecto a la controversia científica. Un convenio de medioambiente acaba elaborándose, constituyendo un acuerdo en materia de diagnósticos y de objetivos a alcanzar así como de soluciones institucionales o técnicas que

32 Faucheux. S., O’Connor. M., «Un concept contreversé : le capital naturel », Cahier $d u$ C3ED, n०99-01, 1999.

${ }^{33}$ Hourcade. J.C., Salles. J-M., Théry. D., « Ecological economics and cientific controverseries. Lessons from some recent policy making in the EEC», Ecological Economics, vol.6, 1992.

${ }^{34}$ Roqueplo. Ph., Pluies acides: menaces pour l'Europe. Paris, Economica, 1988. 
es preciso poner en marcha. Se trata de unos marcos normativos, creados a lo largo de la historia y del proceso de negociación, que están planteados y que permiten a los actores tomar decisiones. Aunque se observe una referencia marcada a los sistemas de derecho de propiedad, no existen reglas generales en la materia y diferentes negociaciones son llevadas a cabo en lo que concierne los diferentes recursos o medios naturales. Algunos convenios medioambientales, como los que conciernen a ciertas zonas de pesca, son ya antiguos y evolucionan con el tiempo. Otros relativos al cambio climático o a la erosión de la biodiversidad están en fase de elaboración. Como lo demuestra el ejemplo de las lluvias acidas, nada garantiza que la respuesta dada por un convenio medioambiental pueda resolver de manera satisfactoria el problema planteado inicialmente.

\subsection{La ecología industrial}

Considerando la base biofísica de los sistemas socioeconómicos, la ecología industrial propone otra vía para conciliar la economía y la ecología y trabajar a favor del advenimiento de un desarrollo sostenible. La idea de considerar el «metabolismo» de las actividades económicas, especialmente agrícolas, es muy antigua ${ }^{35}$. Se encuentra también en la obra de Marx $^{36}$ que se inspira de los primeros estudios realizados por Liebig sobre los ciclos biogeoquímicos. Concibe la humanidad como una verdadera fuerza biogeoquímica y elabora cálculos eco-energéticos. Los años 1970, con la crisis del petróleo, asisten a la extensión de este tipo de análisis. Kneese, Ayres y d’Arge (1970) utilizan el principio de conservación de la materia para modelizar las relaciones entre la economía y el medioambiente, inaugurando estudios sobre el «metabolismo industrial» que no han parado de multiplicarse, en una corriente que ocupa desde entonces un lugar importante en la economía ecológica.

Simultáneamente, la ecología industrial germina en el seno del PNUE, con Strong como director. Quince años más tarde, Frosch y Gallopoulos (1989) publican un texto de referencia en materia de ecología industrial en un número especial de la revista Pour la science, justo después de la publicación del informe Brundtland y antes del desarrollo de la conferencia de Río. Estos autores, que trabajan entonces en General Motors, proponen involucrar el sistema industrial en una profunda reforma de sus prácticas

35 Fischer-Kowalsky. M., « On the history of industrial metabolism », in Bourg. D., Erkman. S., Perspectives on Industrial Ecology. Shefflield, Greenleaf, 2003.

${ }^{36}$ Marx, 1867, 998. 
medioambientales. Una vez más, el sector automovilístico se muestra puntero en la elaboración de modelos de organización del trabajo y de la producción. La difusión y la institucionalización de la ecología industrial se produce rápidamente a lo largo de los años 1990, gracias especialmente al relevo de las consultorías privadas. A su vez, el mundo empresarial se ha reunido para hacer conocer su interpretación del desarrollo sostenible. La ecología industrial es un elemento de esta concepción. Esta perspectiva se dirige a los países del Sur ${ }^{37}$ que se ven enfrentados a fuertes presiones en términos de disponibilidad de los recursos naturales y financieros y se inspiran de los modelos occidentales en materia de producción y de consumo, con sus ventajas e inconvenientes.

\subsubsection{Copiar la naturaleza}

La ecología industrial se presenta como un enfoque preocupado por dar un contenido operativo a la noción de desarrollo sostenible ${ }^{38}$, lo que permite salir del debate estéril que opone la economía a la ecología. Sucede lo mismo con los miembros de Empresas para el medioambiente que reivindican la ecología y no la ideología. Se refieren a la dimensión objetiva de la ciencia ecológica para repensar los procesos de producción y de consumo. Esta idea de considerar de manera unificada la economía de los seres humanos y la economía de la naturaleza goza de cierta historia. Desde su origen, la termodinámica es una ciencia que se ha construido a partir de una reflexión general que abarca los sistemas vivos y los sistemas técnicos. Más allá de las diferencias observables entre estos dos objetos, incita a concebir las maquinas como organismos vivos e inversamente. Esta misma circulación de metáforas y de modelos ha acompañado el desarrollo de la ecología ecosistémica después de la Segunda Guerra mundial. Por ejemplo, una nave espacial construida para un largo viaje es un buen ejemplo de ecosistema ${ }^{39}$. Por lo cual no es de sorprender que «considere el sistema industrial como un caso particular de ecosistema ${ }^{40}$.

37 Erkman. S., Ramaswamy. R., Applied Industrial Ecology: A New Plateform for Planning Sustainable Societies. Bangalore, Aicra Publishers, 2003.

38 Adoue. C., Ansart. A., «L'essor de l'écologie industrielle : une avancée vers le développement durable », Futuribles, n²91, 2003.

39 Odum. E.P., Fundamentals of Ecology. Philadelphia, W.B. Saunders, 1971.

${ }^{40}$ Ekerman. S., Vers une écologie industrielle. Paris, C.L. Mayer-la Librairie, 1998, p.9. 
Se ha dado un paso adicional en esta aproximación al análisis de los sistemas con la perspectiva evolutiva que dibujan algunos ecólogos industriales. Si la vida es «un éxito duradero», no siempre ha sido así. «La vida existe sobre la tierra desde hace 3,5 billones de años, pero solo ha alcanzado un equilibrio duradero a la mitad del camino, aproximadamente al término de dos billones de años» ${ }^{41}$. Estos autores retrazan la evolución hacia la sostenibilidad de la vida en algunas grandes etapas. En el origen, el ecosistema de tipo 1 se instaura en un entorno poco coactivo en el cual puede escoger sus recursos y rechazar sus residuos sin preocuparse de ello. Bajo la presión de la evolución, un ecosistema de tipo 2, más eficaz que el anterior, aparece, con unos flujos internos de materia y de energía superiores a sus flujos externos. No obstante, la necesidad de coger y de rechazar unos elementos en su entorno hace que el sistema se enfrente, a partir de un cierto momento, a los límites de su desarrollo. La evolución ha conducido a la aparición de un ecosistema de tipo 3 cuyos elementos están continuamente reciclados, ya que la energía sigue siendo el único entrante del sistema. El sistema industrial debe seguir esta misma evolución dialéctica: «el ecosistema industrial actual, basado en los combustibles fósiles, se parece a las primeras etapas de la evolución biológica, cuando los organismos más primitivos se procuraban su energía en un stock de moléculas orgánicas acumulado durante el período prebiótico» ${ }^{42}$.

\subsubsection{Una ingeniería ecológica}

Un ecosistema es un sistema ecológico complejo que evoluciona gracias a la interacción de dos componentes: un biótopo y una biocenosis. El biótopo es el conjunto de factores bióticos, de naturaleza física o química, que constituye el entorno vital donde se desenvuelven las especies animales y vegetales. La biocenosis es la totalidad de las especies asociadas a un entono vital, desarrollando una red de interdependencias vía, entre otros aspectos, una cadena alimenticia. Una manera de describir este sistema es traduciendo estos componentes y sus relaciones en cantidades de energía. Midiendo los flujos energéticos que entran y salen, es posible describir el metabolismo del sistema y la eficacidad de las transformaciones energéticas sobre las cuales se fundamenta la cadena alimenticia del ecosistema: es el principio mismo de la eco-energética. La

${ }^{41}$ Ayres. R.U., « Le métabolisme industriel et les changements de l'environnement planétaire », Revue Internationale de sciences sociales, vol.121, 1989, p.402.

42 Ekerman. S., Vers une écologie industrielle. Paris, C.L. Mayer-la Librairie, 1998, p.37-38. 
ecología industrial sigue un enfoque similar para estudiar el metabolismo industrial de los sistemas socioeconómicos. Una vez conocido, se asignan cuatro objetivos: 1) la optimización del uso de la energía y de las materias primas, 2) la minimización de las emisiones contaminantes y el cierre de los flujos que circulan en el interior de los sistemas productivos, 3) la desmaterialización de las actividades económicas, y 4) la reducción de la dependencia hacia fuentes energéticas no renovables.

Más allá del estudio del metabolismo industrial, se pretende fabricar un ecosistema de tipo 3 o, por lo menos, aproximarse en la medida de lo posible a ello. La mejor ilustración de este objetivo es la simbiosis industrial de Kalundborg. Frosch lo describe como «un sistema industrial modélico: una refinería a) utiliza el calor perdido por una central térmica y b) vende el azufre extraído del petróleo a una fábrica química. La refinería propone también sulfato de calcio a un productor de placas murales c) en sustitución del yeso que compra habitualmente. El vapor excedente de la central calienta igualmente el agua de una empresa acuícola d), así como invernaderos y viviendas e). A la imagen de los organismos que, en los ecosistemas, se nutren de los residuos y restos de las demás especies, los subproductos y residuos de empresas sirven de materia prima para la producción de otras empresas. Este conjunto de intercambios energéticos y materiales que vinculan las principales empresas de la zona industrial de Kalundborg permite ahorrar recursos y producir menos residuos finales. En lugar de centrarse en el final del proceso, se intenta evitar producir y emitir nuevos residuos.

\subsubsection{La auto-organización verde}

Si el ejemplo de Kalundborg es tan citado por los ecólogos industriales es porque permite lanzar un mensaje político. Los comentaristas de esta experiencia subrayan que solo se ha tomado conciencia de estas características en 1989, es decir después de treinta años de existencia. En otros términos, esta organización industrial se habría puesto en marcha espontáneamente ${ }^{43}$. La ecología industrial se sitúa en la tradición de internalización de las externalidades, dejando los actores negociar espontáneamente entre ellos la gestión del medioambiente sobre la base de los cálculos coste-ventaja que

43 No obstante, conviene subrayar que ciertos análisis insisten sobre el carácter endógeno y evolutivo del proceso, destacando la estrecha relación entre los agentes y la importancia de la confianza generada entre ellos al compartir espacios sociales al margen del trabajo. 
realizan. Erkman ${ }^{44}$ insiste en que los intercambios de subproductos y de residuos que se desenvuelven entre las diferentes empresas de la simbiosis de Kalundborg obedecen a las leyes del mercado.

Estas entidades pretenden «ganar sobre los dos terrenos», reduciendo el impacto medioambiental de sus procesos de producción y ganando dinero. Esta estrategia doblemente ganadora es a veces calificada de hipótesis de Porter. En todos los casos, el mercado está llamado a jugar un papel de regulación del desarrollo sostenible. «El funcionamiento de un sistema de mercados libres y competitivos, donde los precios integran los costes medioambientales en los demás componentes económicos, constituye el fundamento de un desarrollo sostenible» ${ }^{45}$.

\subsubsection{Las normas de gestión para una auto-regulación}

La literatura del management medioambiental pone el énfasis en el papel del manager en las evoluciones. Se trata de una figura providencial que sabe, decide y convence a los demás sobre los cambios de orientación a realizar. Se genera también un discurso relativo al rol del Estado, puesto que determina el contexto institucional en el cual actúan las empresas. La política medioambiental exigida por los ecólogos industriales consiste en privilegiar las incitaciones financieras y revisar las normas: «los reglamentos deben flexibilizarse con el fin de no estorbar el reciclaje y las demás operaciones de minimalización de los residuos» ${ }^{46}$. Un conjunto de normas técnicas y de gestión debe certificar estas prácticas eco-eficientes y permitir enviar señales de calidad en dirección de los consumidores y de los accionistas. Los labeles están destinados a informar los primeros y los informes medioambientales así como las demás normas de gestión los segundos.

Hoy en día, existe una gran disparidad de prácticas en las empresas comprometidas en estas operaciones de reporting. Varias instancias proponen diferentes series de indicadores, en las cuales las empresas escogen según su deseo. La calidad de estos informes y sus modalidades de validación por los peritos de tasación y los gabinetes

44 Ekerman. S., Vers une écologie industrielle. Paris, C.L. Mayer-la Librairie, 1998, p.26.

45 Schmidheiny. S., Changer de cap. Réconcilier le développement de l'entreprise et la protection de l'environnement. Paris, Dunod, 1992, p.37.

${ }^{46}$ Frosch. R., Gallopoulos. N., « Des stratégies industrielles viables », Pour la science, ${ }^{\circ} 145$, 1989, p.114. 
de auditoría son también variables: algunos se refieren a las prácticas de recogida de datos y de cálculo, mientras que otros se centran en el impacto medioambiental. En la mayoría de los casos, las averiguaciones conciernen los procedimientos. En este caso, se trata de compromisos voluntarios de las empresas: definen ellas mismas los objetivos medioambientales que quieren alcanzar, teniendo en cuenta que la normalización atestigua de que han puesto en marcha unos procedimientos adecuados para ello.

El discurso de las empresas es el de una modificación de su actitud hacia las cuestiones medioambientales. «La industria francesa ha pasado de un actitud reactiva ante las coacciones impuestas por la reglamentación a una actitud proactiva que reivindica la gestión co-responsable del problema del medioambiente. Concierne a todas las funciones de la empresa y se integra progresivamente en todas las reflexiones y acciones de los actores de la empresa». Los empresarios quieren mostrar el carácter responsable de su empresa, «su determinación a continuar sus progresos y a gestionar estos problemas con eficacia y transparencia. Permite también la instauración de relaciones de confianza entre la administración y la industria que deberían conducir a un aligeramiento de los controles». La problemática del desarrollo sostenible se traduce en la empresa por la responsabilidad social y la inversión responsable que pretende conciliar las actividades empresariales con los valores del conjunto de la sociedad, respondiendo a las expectativas de los socios que no se limitan a los accionistas y a los clientes de la empresa.

La auto-reglamentación está considerada como mucho más eficaz que la coacción pública, puesto que supone la adhesión voluntaria de las empresas y asegura la transparencia de los procedimientos puestos en marcha. Se trata ante todo de poner en marcha nuevas políticas medioambientales que tomen en cuenta los intereses de las empresas responsables. Esta aspiración se fundamenta en un análisis desformado de las políticas puestas en marcha desde los años 1970.

\section{ECODESARROLLO, REPARTO MEDIOAMBIENTAL Y DESCRECIMIENTO}

Una serie de investigaciones ponen de manifiesto las cuestiones sociales planteadas por la problemática del desarrollo sostenible. Bien es cierto que este desarrollo se ha producido en un contexto de crisis económica que corresponde también a una crisis de las teorías del desarrollo. Rompiendo con la visión económica dominante, que convierte el advenimiento del desarrollo en la lógica histórica de las sociedades, estos análisis se preguntan sobre la especificidad del no-desarrollo que conocen ciertas regiones del planeta y sobre las posibilidades de un desarrollo alternativo al elegido por los países 
occidentales. El estudio de las sociedades campesinas es una fuente de inspiración para estos teóricos de la alteridad económica. Si algunos desean conservar el objetivo del desarrollo, intentando declinarlo de otra forma, otros hacen un llamamiento a rechazarlo y a instituir otras perspectivas de progreso social. Así, nos invitan a reflexionar sobre los valores económicos dominantes de las sociedades de abundancia. A través del desarrollo sostenible, la interrogación sobre la noción de necesidad está de nuevo en el orden del día por la necesidad de tomar en consideración la problemática medioambiental y el reparto de la riqueza al nivel mundial.

\subsection{El ecodesarrollo}

El ecodesarrollo prefigura y aparece como una expresión competidora del desarrollo sostenible. La noción de ecodesarrollo ha sido propuesta por Strong en 1972 para relanzar el diálogo entre el Norte y el Sur, después de la conferencia de Estocolmo. Sachs, que ha ocupado también altos cargos en los órganos internacionales durante treinta años, se ha convertido en el principal teórico de esta noción. En El descubrimiento del tercer mundo, Sachs (1971) es consciente del europeo-centrismo que se esconde detrás de las teorías elaboradas por los economistas del desarrollo. No obstante, rechaza cualquier abandono de este objetivo, hablando incluso de la dimensión normativa del ecodesarrollo. Prefiere calificar el ecodesarrollo de filosofía del desarrollo e intenta dirigirse hacia los actores que elaboran los proyectos e intervienen concretamente en el campo.

\subsubsection{Reducir las desigualdades}

Según Sachs, el crecimiento económico, incluso si es fuerte y está acompañado por una modernización de las estructuras de producción, no conduce al desarrollo. Por el contrario, desemboca generalmente en un incremento de las desigualdades sociales, que son responsables de una buena parte del deterioro del medioambiente. Se produce un derroche cuando la riqueza de unos conduce al consumo de productos superfluos y cuando la miseria de otros provoca una sobre-explotación de los escasos recursos disponibles. El «mal-desarrollo» es, por lo tanto, un problema general. Lo que exige poner en marcha un programa global de reformas en la manera de tomar las decisiones económicas, con recomendaciones diferenciadas según los países, puesto que las responsabilidades del Norte en la modificación de las relaciones internacionales son 
notables. Se pone el énfasis en los cambios institucionales y políticos necesarios para permitir estas evoluciones que deben producirse en un período de tres o cuatro generaciones. Inspirado por las concepciones de Kalecki, Sachs no cuestiona el crecimiento sino los objetivos desigualitarios que conlleva. Conviene, por lo tanto, actuar sobre su orientación poniendo el excedente económico y el tiempo disponible al servicio del progreso social y de la gestión racional de los entornos naturales. Si el crecimiento es igualitario, las poblaciones aceptarán más gustosamente restringirse en la satisfacción de sus necesidades materiales así como en su demografía.

Al nivel medioambiental, Sachs rechaza la hipótesis de una dotación material y energética ilimitada. Sin embargo, los límites termodinámicos asignados a la actividad económica por Georgescu-Roegan solo son validos en un horizonte temporal lejano. La llegada al estado estacionario, al que tendrá que resignarse algún día, no es para ahora mismo. Existe un desacuerdo entre los partidarios del ecodesarrollo y los defensores de la economía ecológica que se centran más en las prioridades asignadas que en el fondo del problema. Efectivamente, Sachs releva que el crecimiento extensivo está condenado y su interpretación del desarrollo deja un lugar a la posibilidad de un crecimiento material fundado en un uso más racional de la energía y de la materia, lo que demuestra que los límites no están dados una vez para siempre. Ello permite a Sachs definir el ecodesarrollo como un «desarrollo de las poblaciones por ellas mismas, utilizando lo mejor posible los recursos naturales, adaptándose a un entorno que transforman sin destruirlo. Es el desarrollo mismo el que debe estar impregnado, motivado, apoyado por la búsqueda de una equilibrio dinámico entre la vida y las actividades colectivas de los grupos humanos y el contexto espacio-temporal de su implantación». No es la producción y las demandas solventes las que deben ser consideradas inicialmente en sus objetivos económicos, sino las necesidades fundamentales de todas las personas.

\subsubsection{La autonomía de las decisiones y los estilos de desarrollo}

Si el desarrollo sostenible aparece como una cuestión general que se plantea en todos los países, esta debe declinarse diferentemente según los lugares y las circunstancias. La diversidad cultural es reconocida de golpe: todos los grupos sociales tienen el derecho de proseguir sus objetivos en el marco de su cultura específica y de su relación a la naturaleza. Oponiéndose a las estrategias miméticas de desarrollo, la doctrina del ecodesarrollo pertenece a las teorías del desarrollo endógeno. La autonomía de las decisiones debe prevalecer sobre los niveles individual y colectivo, insistiendo sobre el hecho de que la autonomía no significa la autarcía. Importa que cada comunidad defina 
por ella-misma un proyecto social global que respete su propio estilo de desarrollo, es decir la manera según la cual se organizan y gestionan los recursos humanos y materiales en una comunidad.

Se trata, por lo tanto, de responder a las siguientes preguntas: ¿Qué bienes y qué servicios es preciso producir? ¿Para quién? ¿Cómo? Los elementos de respuesta están ofrecidos por el análisis de la estructura de la producción, de las rentas y del consumo, así como por el estudio de la ordenación del tiempo y del espacio, de las conductas y de los valores. En definitiva, se trata de una manera de estar en el mundo que difiere de un sitio a otro y que no se presenta inmediatamente a los ojos de los observadores extranjeros. Lo que implica la necesidad de aprehenderlo correctamente, de hacer un llamamiento a todas las ciencias sociales y, especialmente, a la historia y a la sociología. Se trata, por lo tanto, de relanzar los estudios sobre el desarrollo en una perspectiva interdisciplinar y de no conformarse, considerando las relaciones entre la economía y lo social y las relaciones entre la economía y la ecología.

\subsubsection{La atención prestada al desarrollo local}

El carácter circunstanciado de la cuestión del desarrollo conduce a que el ecodesarrollo tenga aplicaciones en los niveles local y regional ${ }^{47}$. Este pretende poner de manifiesto los recursos específicos de una «eco-región» en vista a la satisfacción de las necesidades fundamentales de la población. Presente desde el origen en el análisis del ecodesarrollo en las sociedades campesinas, esta inclinación se refuerza a partir de los años 1980. En Francia, en el contexto de las primeras leyes de descentralización y de la crisis del Estado de bienestar, el desarrollo regional y local ha sido el objeto de una atención particular por parte de los investigadores del CIRED ${ }^{48}$. El desarrollo regional y local es concebido como una de las vías posibles para superar la crisis económica y medioambiental. Esta reflexión sobre el desarrollo endógeno en otras escalas territoriales pretende articular la lucha contra el desempleo, la protección del medioambiente

47 Sachs. I., Stratégie de l'écodéveloppement. Paris, Economie et Humanismes/Editions ouvrières, 1980, p.76.

${ }^{48}$ Godard. O., Ceron. J-P., Vinaver. K., Passaris. S., «Le développement endogène et la différenciation des espaces de développement: une grille d'analyse pour le développement local», Les Nouvelles de l'Ecodéveloppement, n³5, 1985. 
y el auge de las formas de economía social. El ecodesarrollo debe traducirse por una pluralidad de trayectorias y una diversidad de modelos de economía mixta.

Pero, la prudencia es necesaria y el desarrollo local no puede ser la panacea. El Estado aparece a menudo como un contrapeso a la presión de los intereses locales y ciertas cuestiones medioambientales deben ser abordadas a otros niveles de organización política. Esta perspectiva, teniendo en cuenta el reconocimiento de los problemas globales de medioambiente, ha tomado un peso creciente a partir de la mitad de los años 1980. Sachs ha recordado regularmente el papel que debía desempeñar la ONU en la instauración de un nuevo orden económico internacional. Con el tiempo, las expectativas de una gestión colectiva de los patrimonios comunes de la humanidad por una autoridad mundial no se han atenuado, así como la idea de establecer un foro mundial para discutir sobre las estrategias de desarrollo. En esta difícil dialéctica entre lo local y lo global ${ }^{49}$, se produce una interrogación sobre los espacios de desarrollo pertinentes y sobre las posibilidades de articularlos institucionalmente ${ }^{50}$.

\subsubsection{La elección de las técnicas apropiadas}

Aunque los problemas de desarrollo sean ante todo de orden institucional y político, la cuestión de las decisiones técnicas es central en el pensamiento del ecodesarrollo. No se puede analizar la técnica únicamente a través de los conceptos de capital y de trabajo, y su grado de abstracción. En la óptica del ecodesarrollo, es considerado como un fenómeno multidimensional que exige tomar en consideración el tipo de energía y de recursos empleados para asegurar su funcionamiento, sus resultados, su complejidad, la calificación de la mano de obra que requiere o su impacto medioambiental. Por lo tanto, se pone el énfasis en la noción de técnicas apropiadas al contexto cultural, institucional y ecológico ${ }^{51}$, subrayando que no son únicamente técnicas intermedias. Rompiendo con la estrategia de transferencia mimética de las técnicas del Norte hacia el Sur, las técnicas apropiadas deben provenir de investigaciones específicas que res-

49 Vivien. F-D., Zuindeau. B., «Le développement durable et son espace: antécédents intellectuels et questions pour l'avenir», Cahiers lillois d'économie et de sociologie, n³7, 2001.

${ }^{50}$ Zuindeau. B., Développement durable et territoire. Villeneuve-d'Ascq, Presses Universitaires du Septentrion, 2000.

51 Théry. J., «Plaidoyer pour Développer des technologies plus appropriées et passer du mimétisme au pluralisme technologique», Revue tiers-monde, vol.22, nº8, 1981. 
pondan a las necesidades de los países del tercer mundo y de una selección entre las técnicas disponibles al nivel internacional. Esta selectividad debe desembocar sobre la coexistencia de varios tipos de técnicas en el seno de cada economía nacional.

La prudencia ecológica es uno de los elementos a considerar en la elección de las técnicas de producción. Si los ecosistemas se caracterizan por su fragilidad, la naturaleza no sabe necesariamente mejor que las personas lo que es bueno para ella. Hay que aprender a respetar la naturaleza y a establecer con ella una relación simbiótica. Este principio encuentra su traducción en las listas exploradas en materia de elección de técnicas. Conviene dar la prioridad a las técnicas que preservan los recursos naturales, se insertan en los ciclos biogeoquímicos y permiten el reciclaje. La utilización de recursos renovables en lugar de recursos no renovables es también deseable. La idea de una revolución industrial adaptada a los países del Sur, fundamentada en lo vegetal, como material de construcción o como recurso energético, que proviene de productos forestales, de culturas energéticas o de residuos agrícolas, es uno de los grandes objetivos de Sachs.

\subsubsection{La planificación participativa}

El ecodesarrollo no se reduce a las elecciones técnicas. Quiere ser un instrumento esencial para la prospectiva y la exploración de las opciones de desarrollo. La acción del Estado se orienta tradicionalmente hacia la economía del desarrollo, puesto que la planificación es uno de sus instrumentos privilegiados. En este ámbito, la experiencia soviética ha constituido un modelo de referencia durante un largo período, simbolizando el paso rápido de una sociedad rural a una sociedad moderna, capaz de rivalizar con los Estados Unidos en la carrera al armamento y a la conquista espacial. El planificador del ecodesarrollo debe, lo más a menudo, departirse de la voluntad de optimizar sus decisiones. La optimización es inalcanzable teniendo en cuenta la multiplicidad de los elementos a tener en cuenta y la falta de información relativa a un cierto número de dimensiones de los problemas. Por lo tanto, conviene darle de nuevo un sentido político a la compresión de los procesos decisorios, de las estrategias de los actores y de las relaciones de fuerza con los cuales el planificador debe componer.

La planificación es concebida como un lugar de discusión, de negociación y de compromiso, de modo que el planificador sea un animador y un negociador. Aparece más como una figura dotada de ciertas cualidades que como un sistema y unos procedimientos de planificación. Existe una multiplicidad de dimensiones y de variables que el planificador debe aprehender y sobre los cuales debe saber incidir: el reparto de 
la riqueza, la estructuración del consumo, las técnicas empleadas, las modalidades de utilización de los recursos naturales, la ocupación de los suelos o el comercio exterior. Para orientar su intervención, este planificador debe disponer de una serie de indicadores ecológicos y sociales que dan cuenta de la multidimensionalidad de la realidad. Más allá de esta recogida de datos, todas las disciplinas están convocadas para establecer una racionalidad social. Es preciso poner en marcha una planificación participativa que permita un justo equilibrio entre el mercado, el Estado y la sociedad civil. Esta, solo cobra sentido si se acompaña de un esfuerzo de educación sobre las obligaciones: si se espera de ellas que puedan decidir en las mejores condiciones y que pueden tener múltiples dimensiones, es indispensable realizar importantes esfuerzos de formación. Se reconoce la necesidad de construir una democracia más amplia.

\subsection{El reparto medioambiental}

Una tradición en economía del desarrollo pretende demostrar que el desarrollo y la ausencia de desarrollo son las dos caras de la misma dinámica del capitalismo, que prospera estableciendo relaciones de interdependencia entre un centro y una periferia. Las teorías estructuralistas y marxistas proponen unas teorías del subdesarrollo. Las economías del Sur son extravertidas y están vinculadas a los mercados exteriores, a la evolución de los precios mundiales, a las decisiones de las multinacionales, lo que hace que el excedente económico que producen sea captado por las economías del Norte. Estas teorías no toman en consideración la problemática medioambiental. Es precisamente lo que pretenden hacer Joan Martinez-Alier y su equipo (2002) con el concepto de «intercambio ecológicamente desigual» que amplia la perspectiva abierta anteriormente.

La explotación del Sur por el Norte supone la desigualdad de los salarios concedidos a los trabajadores de los diversos espacios económicos. Permite que unas cantidades iguales de trabajo no sean pagadas al mismo precio por los actores que participan en los intercambios internacionales. El intercambio ecológicamente desigual describe el hecho que ciertos productos son exportados por países pobres a precios que no cubren los costes salariales y medioambientales inducidos por sus producciones. Así, numerosos países del Sur se ven obligados a practicar una forma de dumping medioambiental y social exportando a bajo precio los recursos naturales o productos básicos hacia los países del Norte. Se pueden citar las actividades de extracción de petróleo, de mineral, de transformación de los bosques en pastos o la producción de café.

Si Cabeza-Gutés y Martinez-Alier no rechazan el comercio internacional como tal y se muestran partidarios de unos intercambios comerciales más equitativos y más 
respetuosos del medioambiente, algunos miembros de la economía ecológica hacen un llamamiento a romper con la división internacional del trabajo y a buscar, de manera pragmática, una mayor autonomía, incluso una autosuficiencia de las administraciones públicas locales ${ }^{52}$.

\subsubsection{Los retos redistributivos de las cuestiones medioambientales}

Martinez-Alier pone el énfasis sobre el problema del reparto ecológico ${ }^{53}$. Así, sitúa la cuestión de la pobreza en el centro del reto de la sostenibilidad. Basándose en los ejemplos de los movimientos sociales de los países del tercer mundo, quiere demostrar que, por una parte, la pobreza no se puede considerar solamente como una amenaza para el medioambiente y, por otra parte, la protección del medioambiente no es únicamente un lujo de los ricos. En otros términos, existe un «ecologismo de los pobres» que lucha por un mejor reconocimiento de sus derechos, incluso en el ámbito medioambiental. Esta perspectiva es aún más importante a tener en cuenta ya que políticas medioambientales conflictivizan las relaciones Norte-Sur, sea a través de la instauración de un permiso de emisión de $\mathrm{CO} 2$ negociable, en el caso de la prevención contra el cambio climático, sea vía un comercio internacional de genes, en el marco de la lucha contra la erosión de la biodiversidad.

Se contemplan importantes efectos nefastos. Por una parte, porque estas políticas se fundamentan en el reconocimiento de los nuevos derechos de propiedad, en lo que se refiere al medioambiente (derecho de contaminar y posteriormente derecho de propiedad intelectual). Para los titulares, estos derechos representan nuevas dotaciones, nuevos activos y nuevos patrimonios que, cuando son objeto de transacciones, se corresponden con las transferencias de ingresos y de riqueza. Por otra parte, porque los precios actuales en los que se intercambian estos nuevos tipos de derechos dependen ampliamente del reparto inicial de la riqueza y de los ingresos de los actores en presencia. No conviene olvidar que el precio es la expresión de una relación de fuerzas entre varias partes implicadas. Pero, cabe pensar que los pobres venderán sus derechos a un

52 Damian. M., Graz. J-C., «Les grands paradigmes», en Damian. M., Graz. J-C., Commerce international et développement durable. Paris, Economica, 2001, p.41.

${ }^{53}$ Martinez-Alier. J., O'Connor. M., «Ecological and economic distribution conflicts», in Costanza. R., et al., Getting Down Earth. Practical Applications of Ecological Economics. Washington, Island Press, 1996. 
precio reducido. Lo que plantea la necesidad para los movimientos sociales de influir sobre las negociaciones medioambientales si no se quieren generar nuevas exclusiones y desigualdades sociales.

\subsubsection{Las enseñanzas de las políticas de regulación}

Es todavía demasiado pronto para evaluar los efectos de las políticas internacionales sobre el cambio climático y la biodiversidad. Estos dependen de las reglas aprobadas en materia de regulación, de concesión inicial de derechos y cuotas y de condiciones de su transferibilidad. Guardando en la mente que los sistemas de regulación dotados de reglas diferentes producen efectos económicos y sociales variados, no es interesante considerar el ámbito de la pesca que, desde hace más de veinte años, ha instaurado unos sistemas de cuotas individuales transferibles para intentar regular las extracciones en el ámbito pesquero. El ejemplo de semejante sistema, entrado en vigor en Islandia en 1984, es particularmente instructivo desde el punto de vista de los efectos redistributivos. Estas cuotas tienden a disminuir el número de actores en presencia y a concentrar la riqueza en las manos de un pequeño número de actores integrados verticalmente. Ciertas empresas pesqueras que han recibido cuotas no las utilizan completamente y las alquilan a otros actores más modestos, lo que acaba siendo muy lucrativo para los primeros, en la medida en que les garantiza un abastecimiento regular, evitando los gastos vinculados a la actividad pesquera y a un coste que se valora en la mitad del precio del mercado. Así, el sistema de cuotas hace que se pueda vender pescado que todavía no ha sido pescado.

Esta separación entre los procesos de apropiación y de producción modifica las relaciones sociales en vigor en el sector de la pesca de alta mar. Es preciso saber que la relación de producción que vincula el patrón-pescador y los marineros-pescadores no es el que une un empleador a su asalariado. Existe una cierta solidaridad entre los primeros por el hecho de compartir el riesgo durante las campañas, lo que se traduce por el reparto de los beneficios de la explotación que consta de una parte fija y de una parte variable vinculada al volumen de negocios. Actualmente, ciertos propietarios de cuotas pueden evitar los riesgos vinculados a su actividad profesional, mientras que los patrones-pescadores están incitados a rebajar los salarios de los marineros-pescadores para mantener sus beneficios. Se registra así una disminución de la renta destinada al equipaje.

El derecho de pesca se ha convertido en un nuevo factor de producción, frente al capital y a la fuerza de trabajo, cuyos poseedores esperan recibir una remuneración. 
Este poder puede ser utilizado por los «señores del mar» o los «reyes de las cuotas» para negociar con la autoridad reguladora, presionándola para que las condiciones de transferencia de cuotas, el control de los precios y las reglas relativas a las posiciones dominantes sean flexibilizadas a su favor. Conviene también preguntarse sobre las desigualdades intergeneracionales que son susceptibles de producirse con la instauración de estos sistemas de cuotas transferibles. Es la primera generación que recibe la renta, bajo la forma de cuotas concedidas inicialmente, que tiene muchas posibilidades de beneficiarse de la nueva riqueza creada, mientras que las generaciones siguientes deberán procurarse este suplemento.

\section{3. ¿Hacia el descrecimiento?}

Radicalizando todavía más el debate en torno a la noción de desarrollo sostenible, algunos economistas proponen mantener la posición contraria con respecto al objetivo de crecimiento e instaurar en su lugar un descrecimiento. Estas propuestas han despertado un gran interés y han generado una viva controversia, incluso entre los partidarios del descrecimiento. Algunos de ellos han hecho un llamamiento a rechazar la idea misma de desarrollo, acusado de ser la mascara detrás de la cual avanza la occidentalización del mundo y la mercantilización de las relaciones sociales. Esta posición mantenida por Latouche (1994) rechaza el desarrollo y reconstruye esta noción que tiene un contenido normativo. El desarrollo sostenible le aparece como un «concepto pretexto» que permite hacer durar el desarrollo. Latouche y los defensores del post-desarrollo proponen sustituir este objetivo por el de «descrecimiento duradero».

Por el contrario, otros autores como Harribey critican el desarrollo llevado a cabo por las políticas liberales y utilizan la noción de desarrollo sostenible para defender un modelo alternativo de desarrollo. Antes de instaurar una desaceleración del crecimiento, las relaciones de producción capitalista deben ser cambiadas y las desigualdades de riqueza deben ser combatidas, teniendo en cuenta que un período de recuperación debe ser acondicionado para que las poblaciones que lo necesitan puedan ver su nivel de vida aumentar. En ambos casos, más allá de las oposiciones que afectan en particular al análisis del capitalismo, se trata de reinventar un imaginario en materia de cambio social. 


\subsubsection{El descrecimiento}

El término de descrecimiento está asociado a la obra de Georgescu-Roegan (1993) que debe ser considerado como un economista del desarrollo. Su principal mérito ha sido reflexionar sobre la termodinámica del desarrollo occidental. Pone el énfasis en las innovaciones técnicas fundamentales que han permitido a la humanidad utilizar nuevas fuentes de energía. Desde este punto de vista, la historia humana solo ha conocido algunos momentos decisivos: la domesticación del fuego, la utilización de las energías fósiles, el consumo del carbón y del petróleo. El problema de estas técnicas estriba en que acaban agotando el combustible que las hace vivir. Lo que conduce a una concepción trágica de la historia de la humanidad que está marcada por las luchas que enfrentan los individuos a los Estados para poseer los recursos energéticos y materiales. Esta perspectiva conduce a reconsiderar la revolución industrial como un elemento esencial del imaginario desarrollista. Estudiando las primeras máquinas a vapor, al inicio del siglo XIX, la revolución de la capacidad productiva que inducen modifica la relación del ser humano a la naturaleza.

Se trata de oponer un pensamiento de los límites a esta desmesura. GeorgescuRoegan $^{54}$ es uno de los únicos economistas en haber reconocido la pertinencia del primer informe del Club de Roma, mientras que sus críticos se han limitado a aspectos menores. Sin embargo no está convencido ni por el estado estacional ni por la noción de desarrollo sostenible. Preconiza el descrecimiento, aún siendo consciente de la necesidad primordial de mejorar las condiciones materiales de las poblaciones pobres. No ha cesado de recordar que, cada vez que se produce un automóvil, se utilizan cantidades de baja entropía que podrían ser usadas para fabricar carros y palas útiles para los campesinos del tercer mundo. A la espera de hipotéticas técnicas susceptibles de tomar el relevo de las que utilizan las energías fósiles, pone de manifiesto las medidas destinadas a reducir el derroche y a minimizar los arrepentimientos futuros, permitiendo que las dotaciones energéticas y materiales duren lo más tiempo posible. Para ello, hace un llamamiento a recurrir a las innovaciones técnicas así como a una gestión rigurosa de los recursos a través de unos instrumentos cuantitativos que permitan poner en marcha una estrategia de conservación general planificado al nivel mundial. Sin

${ }^{54}$ Georgescu-Roegan. N., «L'énergie et les mythes économiques», in La décroissance. Paris, Sang de la terre, 1975, p.376. 
embargo, Georgescu-Roegan ${ }^{55}$ insiste en la necesidad de actuar sobre la demanda de los productos en lugar en incidir sobre la oferta.

\subsubsection{La sociabilidad}

Por ciertos aspectos, estas propuestas se asemejan a la crítica del crecimiento elaborado por Illich (1973) que pone el énfasis en los límites organizativos a los que se enfrenta la creación de los nuevos bienes. La tesis central de Illich es que la «religión del crecimiento» legitima un proyecto tecnicista que aspira a que la fabricación industrial de la existencia sustituya el invento de la vida por los individuos. Existe dos modos de producción de los valores de uso: un modo autónomo, por el cual los individuos responden por ellos mismos a sus necesidades, y un modo heterónomo que produce unas mercancías puestas a la disposición de las personas por la mediación de un mercado o de una institución no mercante. Pero, debido a su eficacidad, el modo heterónomo tiene cierta tendencia a imponerse al modo autónomo hasta convertirse en un «monopolio racial», es decir en una situación donde la producción industrial destruye cualquier posibilidad de recurrir a otros medios para satisfacer sus necesidades. A partir de este umbral, se observa una contra-productividad, en el sentido de que las instituciones acaban produciendo el contrario de lo que deberían producir. Sin embargo, privado de su autonomía, cortado de los demás y del mundo, el individuo no tiene otra posibilidad que de dirigirse hacia la industria, lo que reduce más aún su autonomía y refuerza la obligación de consumir unos servicios producidos industrialmente. La búsqueda del bienestar conduce a una pérdida de control cada vez más grande de su existencia por parte de las personas.

Ante esta evolución, Illich hace un llamamiento a los individuos para que retomen el control de sus vidas y construyan una sociedad sociable, donde las personas controlan los instrumentos que les rodean ${ }^{56}$. So es cuestión de hacer desaparecer la técnica moderna sino de preguntarse sobre sus excesos. La sinergía entre los modos de regulación autónomo y heterónomo solo es posible dentro de algunos límites, lo que nos conduce a plantear el problema de la definición de los umbrales de desarrollo a partir de los cuales la articulación entre estos dos

55 Georgescu-Roegan. N., «De la science économique à la bio-économie», Revue d'économie politique, vol. 88,1978 , p.376.

56 Illich. I., La convivialité. Paris, Seuil, 1973, p.13. 
modos de regulación es imposible. La determinación del límite no es fácil. El debate sobre el control de los instrumentos debe ser objeto de una decisión popular y no quedar entre las manos de los expertos. Según Illich, solo una reducción del consumo energético permitirá acceder a unas sociedades democráticas, lo que supone una autolimitación de las necesidades y la elaboración de una norma de lo que es suficiente. No es cuestión de renunciar a los placeres, sino de eliminar aquellos que perjudican la relación al prójimo. Si esta problemática es valida para los países industrializados, interesa también a los países del tercer mundo por la posibilidad que ofrece de no pasar por la era industrial, sino de acceder directamente a un «equilibrio postindustrial».

\subsubsection{Una norma de lo que es suficiente}

Esta búsqueda de autonomía de los individuos conduce igualmente a considerar de manera crítica los lazos históricos y psico-sociológicos que unen el productivismo, el consumismo y la organización del trabajo. Gorz (1988) recuerda como los primeros industriales han tenido dificultades para lograr por parte de los obreros un trabajo continuo, regular y a jornada completa, a pesar de prometerles sueldos más elevados. Semejante resistencia se encuentra hoy en día en los países en vía de desarrollo. Estos obreros trabajaban el tiempo que les era necesario para atender a sus necesidades. Esta limitación de las necesidades permitía una autolimitación del esfuerzo de cada uno y del trabajo de todos. Basándose en las posibilidades ofrecidas por la técnica, ha desposeído los trabajadores de los instrumentos de producción, del producto de su trabajo y del trabajo mismo, para que la producción pueda emanciparse de lo que es suficiente.

El invento de la fábrica ha permitido la modificación de la relación a la naturaleza y el empoderamiento del capitalista sobre el proceso productivo. Ha disminuido el sueldo de los obreros para que trabajen más de lo necesario. Poco a poco, se ha instaurado una disyunción entre el tiempo laboral y el tiempo privado. La pérdida de sentido se ha instalado, ya que el trabajo es vivido por la mayoría de estos individuos como la manera de ganar un salario. Paralelamente, se ha asistido a la creación de un número creciente de necesidades a satisfacer, puesto que los individuos compran ciertos productos por falta de tiempo para poder realizar estas tareas ellos mismos. El consumo mercante ha aumentado igualmente con el juego de un fenómeno de compensación existencial.

La salida de esta dinámica obliga a aceptar ciertas renuncias. El reto actual según Gorz es de instituir políticamente una norma de lo que es suficiente relativamente a las condiciones de vida contemporáneas. Esta reducción del consumo mercante, este 
descrecimiento de la economía ${ }^{57}$ pasa por un reparto diferente de la mejora de la productividad y una reducción del tiempo de trabajo, concebida como una política a largo plazo $^{58}$, siempre y cuando se garantice una renta suficiente independientemente de la duración del trabajo y que se produzca una reparto del trabajo de manera que todo el mundo pueda trabajar menos y mejor. Este tiempo liberado debe permitir una autonomía de los individuos, la autoproducción, la constitución de redes, de solidaridades, de cooperaciones y de inversiones en el ámbito político. En otros términos, se trata de definir de nuevo las fronteras de la racionalidad económica y de las relaciones mercantes, las que deben ser puestas al servicio de otras cosas que no sean ellos mismos y de obrar a favor de un post-capitalismo.

\section{CONCLUSIÓN}

Recordemos que este artículo se ha interesado por las teorías económicas del desarrollo sostenible que se encuentran en el centro del debate político e intelectual, tanto en los países desarrollados como en los países emergentes. Ha intentado reflejar de manera precisa y crítica: 1) las teorías del crecimiento duradero, 2) el pensamiento de la economía ecológica y de la ecología industrial, y 3) las concepciones del ecodesarrollo, del reparto medioambiental y del descrecimiento.

Más precisamente, para responder al reto del desarrollo sostenible, la teoría neoclásica propone esencialmente la acumulación del capital y una extensión del ámbito de la regulación mercante, con una intervención del Estado en lo que concierne a algunos ámbitos. Dicho de otra forma, los problemas de pobreza, de contaminación y de agotamiento de los recursos naturales se resolverán reforzando la lógica económica dominante. Cree en la sostenibilidad del capitalismo y en las virtudes de la regulación mercante que comparten numerosas instituciones internacionales. Esta construcción conceptual está elaborada desde los años 1960 y apenas ha cambiado desde entonces. El progreso técnico y el principio de sustitución constituyen las claves de esta concepción del desarrollo sostenible.

El problema es que las modalidades consideradas no obedecen a esta lógica. En todos los casos se trata de modelos de planificación, lo que no cuadra con la defensa

57 Gorz. A., Capitalisme, socialisme et écologie. Paris, Galilée, 1991, p.172.

58 Attac, Le développement a-t-il un avenir? Pour une société économe et solidaire. Paris, Mille et une nuits, 2004, p.222. 
del capitalismo. Todos los problemas de coordinación, asegurados por el mercado, ya están resueltos porque un solo actor decide o porque hay un perito-tasador que asegura el espinoso problema de la coordinación de los agentes. Además, la auto-regulación mercante no ha sido demostrada en el marco neoclásico. Por el contrario, la intervención del Estado es indispensable para apoyar la inversión, la concesión y el respeto del derecho de propiedad o la recaudación de impuestos. Las políticas públicas que pueden traducirse en recomendaciones concretas son muy genéricas.

Por su parte, en lugar de querer integrar el medioambiente en la esfera económica, la economía ecológica se propone definir las condiciones de inserción de la actividad económica en la biosfera a través de un conjunto de normas socio-medioambientales. Pero, no es suficiente aproximar algunos datos económicos y medioambientales. Los convenios medioambientales que se elaboran se enfrentan a unas incógnitas científicas y a una falta de voluntad política. Una dificultad adicional estriba en la ausencia de separación entre la ciencia y la política en el establecimiento de estas normas. Por el contrario, la interacción es notable entre estos dos mundos y conduce las negociaciones hacia las trayectorias, sin saber si responderán a los problemas planteados. Otras dificultades se refieren al establecimiento de la lista de los convenios necesarios a la toma en consideración del capital natural crítico y a la puesta en coherencia de las diversas modalidades de regulación que tratan los fenómenos que interactúan.

Más allá de estos problemas prácticos, conviene subrayar la ambigüedad de esta corriente de pensamiento que se caracteriza por una gran diversidad de puntos de vista y de posicionamientos políticos. Si la economía ecológica se opone al reduccionismo de la teoría neoclásica, hace referencia a la racionalidad económica. Asimismo, la referencia a los modelos bio-económicos no es específica a la economía ecológica. La utilización de la noción de capital natural conduce a una visión muy economicista e instrumental de la naturaleza. A su vez, si la economía ecológica plantea la cuestión de la transmisión del stock de recursos, ello nos debe conducir a reflexionar sobre el concepto de patrimonio natural, que ofrece una alternativa al referencial económico estándar. Conduce igualmente a plantear nuevas cuestiones porque la patrimonialización es un fenómeno complejo que pone en juego la constitución de comunidades humanas en torno a ciertos objetos con el fin de inscribirse de manera particular en el tiempo ${ }^{59}$.

${ }^{59}$ Barthélemy. D., Nieddu. M., Vivien. F-D., « Externalités ou production de patrimoines? Les enseignements de travaux récents sur l'agriculture et l'environnement », Géographie, Economie et Société, vol.6, n³, 2004. 
La ambigüedad es superior aún cuando se considera la ecología industrial. Este enfoque puede ser recuperado por el mundo empresarial que pretende encarnar el desarrollo sostenible. Abre la vía al eco-capitalismo. No obstante, la problemática de la instauración de límites globales sigue vigente puesto que la disminución del consumo energético y material individual puede ser compensada por un aumento global del consumo de productos. Por ejemplo, se registra un menor consumo de los carburantes por los nuevos vehículos, a pesar de un aumento del tráfico automovilístico. Se plantea igualmente la cuestión de los contra-poderes que se fundamentan en compromisos voluntarios y en asociaciones con ONG cuyas posturas críticas hacia el capitalismo se han suavizado con el transcurso del tiempo.

Por último, El desarrollo sostenible conduce a replantear la cuestión del desarro1lo, sabiendo que se trata de una perspectiva teórica que ha tenido cierta tendencia a desaparecer desde los años 1980, especialmente como consecuencia del auge de las propuestas neoclásicas en materia de crecimiento y de comercio internacional. Las cuestiones de la modificación de las relaciones sociales y de las representaciones que le son asociadas así como de las posibilidades ofrecidas a otro tipo de desarrollo siguen vigentes. Ello nos conduce a preguntarnos sobre las evoluciones contemporáneas del capitalismo así como a comprender el sentido de las protestas y luchas sociales que se producen hoy en día tanto en el Norte como en el Sur. Si las aspiraciones a cambiar el mundo para convertirlo en más solidario están presentes, las vías a seguir no están trazadas. La complejidad proviene en parte de la ampliación del abanico de temas a abordar que mantienen una relación con el desarrollo sostenible. Así, la cuestión del lugar del trabajo en las sociedades contemporáneas conduce a preguntarse sobre las modalidades de funcionamiento de los sistemas de protección social, lo que conduce a abordar los problemas de financiación de la economía.

Hay que reconocer que las cuestiones políticas planteadas no tienen contestación. ¿Cómo se puede saber, si conviene recurrir a ciertas formas de planificación en materia de gestión de los recursos naturales, si es preciso obrar a favor del advenimiento de una democracia técnica, si es necesario repartir el empleo de otra forma o si es indispensable definir normas de lo que es suficiente? Se observa que las opciones políticas previstas por los autores difieren. En lo que respecta al último objetivo, Illich evoca algo que se parece a la conversión religiosa, mientras que otros consideran que es el papel de la negociación colectiva llevada a cabo por los sindicatos o el gobierno, cuando los últimos apuestan por confiar en los colectivos menos institucionalizados y en formas de militancia menos convencionales.

Después de haber presentado las teorías del desarrollo sostenible, nos encontramos con algunas respuestas y muchas preguntas. Ese era el objetivo de este artículo con el 
fin de construir un espacio de discusión sobre la noción de desarrollo sostenible; más aún sabiendo que los principales conceptos de crecimiento, desarrollo y medioambiente son controvertidos en el seno de las ciencias sociales y económicas. Es lo que sucede con las definiciones, teorías y criterios utilizados para dar cuenta de las relaciones existentes entre los diferentes elementos y sus evoluciones. Para intentar aclarar el debate, estas teorías proponen un amplio abanico de objetivos: desde la búsqueda del crecimiento y de la acumulación del capital, hasta el cuestionamiento social y cultural, sinónimo de eco-socialismo, pasando por las propuestas de regulación ecológica del capitalismo. Más allá de este debate sobre la orientación deseable del cambio social, existe una discusión sobre las fuerzas sociales generadoras de futuro y sobre los medios de acción que tienen a su disposición.

Si algunos investigadores confían plenamente en el juego de la racionalidad económica y de los precios para regular las coacciones sociales y medioambientales, otros consideran que es conveniente fijar unas normas fuera de la esfera mercante gracias a unas instituciones particulares. Otros analistas asumen su posicionamiento político poniendo el énfasis en las movilizaciones a llevar a cabo y en las relaciones de fuerza a establecer en el marco de elecciones técnicas, de políticas medioambientales y de negociaciones comerciales. En materia institucional, el debate sobre el funcionamiento de los sistemas de derecho de propiedad aparece como central hoy en día. En este caso también, el debate gira en torno a los tipos de normas a establecer y sobre los actores capaces de fijarlos y de hacerlos respetar: las administraciones públicas o los actores privados, las empresas multinacionales o las ONGs. La problemática del desarrollo sostenible nos obliga a replantear el conjunto de las categorías de la economía política y a revisar la historia del pensamiento económico. De este modo, conviene reconsiderar la relación que mantiene la economía con las demás ciencias sociales y especialmente los vínculos entre la economía, la política y la sociedad.

\section{BIBLIOGRAFÍA}

Adoue, C. y Ansart, A., «L'essor de l'écologie industrielle : une avancée vers le développement durable», Futuribles, núm. 291, 2003.

Alchinn, A. A. y Demsetz, H., «The prosperity right paradigm», Journal of Economic History, vol. 33, núm. 1, 1973.

Arrow, K. et al., « Economic growth, carrying capacity, and the environment», Science, vol. 268, 1995. 
Attac, Le développement a-t-il un avenir? Pour une société économe et solidaire, París, Mille et une nuits, 2004.

Ayres, R. U., « Le métabolisme industriel et les changements de l'environnement planétaire», Revue internationale de sciences sociales, vol. 121, 1989.

BARnETT, H. J., «Scarcity and growth revisited», en V. Kerry Smith, Scarcity and Growth Reconsidered, Baltimore, John Hopkins University Press, 1979.

Barthélemy. D.; Nieddu, M. y Vivien, F.-D., « Externalités ou production de patrimoines? Les enseignements des travaux récents sur l'agriculture et l'environnement», Géographie, Economie et Société, vol. 6, núm. 3, 2004.

BecKerman, W., «Economists, scientists, and environmental catastrophe», Oxford Economic Papers, vol. 24, núm. 3, 1972.

- «Economic growth and the environment: Whose growth? Whose environment?», World Development, vol. 20, núm. 4, 1992.

— «Sustanaible development: is it a useful concept?», Environmental Values, vol. 3, 1994.

Carpintero, O., « Deterioro ecológico, crecimiento económico y sostenibilidad ambiental en España», Sociedad y Utopía: Revista de ciencias sociales, núm. 20, pp. 111-128.

Chevé, M. y Ragot, L., «La croissance endogène durable», en Schubert. K., Zagamé. P., L'environnement, une nouvelle dimension de l'analyse économique, Paris, Vuibert, 1998.

Cole, M. A., «Environmental optimists, environmental pessimists and the real state of the world», The Economic Journal, vol. 113, 2003.

Costanza, R., Ecological Economics: the Science and Management of Sustainability, Nueva York, Columbia University Press, 1991.

Costanza, R. y Daly, H. E., «Natural capital and sustainable development», Conservation biology, vol. 6, núm. 1, 1992.

DaLy, H. E., «Entropy, growth, and the political economy of scarcity», en Kerry Smith. V., Scarcity and Growth Reconsidered, Baltimore, John Hopkins Press, 1979.

- Beyond Growth. The Economics of Sustainable Development, Boston, Beacon Press, 1996.

Damian, M. y Graz, J.-C., «Les grands paradigms», en Damian. M., Graz. J-C., Commerce international et développement durable, Paris, Economica, 2001.

Ekrman. S., Vers une écologie industrielle, Paris, C. L. Mayer-la Librairie, 1998.

Erkman. S., Ramaswamy. R., Applied Industrial Ecology: A New Plateform for Planning Sustainable Societies. Bangalore, Aicra Publishers, 2003.

FIscher-Kowalsky. M., «On the history of industrial metabolism», en Bourg. D., Erkman. S., Perspectives on Industrial Ecology, Shefflield, Greenleaf, 2003.

Faucheux, S. y O’Connor. M., «Un concept contreversé: le capital naturel», Cahier du C3ED, núms. 99-01, 1999.

Foray, D., L'économie de la connaissance, Paris, La Découverte, 2000. 
Frosch, R. y Gallopoulos, N., «Des stratégies industrielles viables», Pour la science, núm. 145, 1989.

Georgescu-Roegan, N., «L'énergie et les mythes économiques», en La décroissance, Paris, Sang de la terre, 1975.

— «De la science économique à la bioéconomie», Revue d'économie politique, vol. 88, 1978.

Godard. O.; Ceron. J.-P.; Vinaver, K. y Passaris, S., «Le développement endogène et la différenciation des espaces de développement: une grille d'analyse pour le développement local», Les Nouvelles de l'Ecodéveloppement, núm. 35, 1985.

Gorz, A., Capitalisme, socialisme et écologie, Paris, Galilée, 1991.

Grossman, G. M. y Krueger. A. B., «Environmental impacts of a north-american freee trade agreement», en Garber. P. M., The Mexico-US Free Trade Agreement. Cambridge, The MIT Press, 1993.

Guellec, D. y Ralle, P., Les Nouvelles Théories de la croissance, Paris, La Découverte, 1995, p. 3.

Hourcade, J. C.; Salles, J.-M. y Théry, D., «Ecological economics and cientific controverseries. Lessons from some recent policy making in the EEC», Ecological Economics, vol. 6, 1992.

Illich, I., La convivialité, Paris, Seuil, 1973.

Martinez-Alier, J. y O’Connor, M., «Ecological and economic distribution conflicts», en Costanza. R. et al., Getting Down Earth. Practical Applications of Ecological Economics, Washington, Island Press, 1996.

Martinez-Alier, J., «Some issues in agrarian and ecological economics, in memory of Georgescu-Roegan», Ecological Economics, vol. 22, 1997.

NAREDo, J. M., El proceso industrial visto desde la economía ecológica, Economía industrial, 1994.

Odum, E. P., Fundamentals of Ecology, Philadelphia, W. B. Saunders, 1971.

Passet, R., L'économique et le vivant, Paris, Payot, 1979.

Pearce, D. W. y Turner, R. K., Economics of Natural Resources and the Environment, Londres, Harvester Wheatsheaf, 1990.

Robinson, J., «Kalecki et Keynes», en Contributions à l'économie contemporaine, Paris, Economica, 1984.

RoQueplo, Ph., Pluies acides: menaces pour l'Europe, Paris, Economica, 1988.

Rostow, W. W., Les étapes de la croissance économique, Paris, Seuil, 1963.

- L'ultimatum de l'an 2000. Chances de survie de l'économie mondiale, Paris, Econmica, 1981.

SACHS, I., Stratégie de l'écodéveloppement, Paris, Economie et Humanismes/Editions ouvrières, 1980. 
Schmidheiny, S., Changer de cap. Réconcilier le développement de l'entreprise et la protection de l'environnement, Paris, Dunod, 1992.

Selden, T. M. y Song, D., «Environmental quality and development: is there a Kuznets curve for air pollution emissions?», Journal of Environmental Economics and Management, 1994.

Sмiтh, F. L., «La protection de l'environnement par la privatisation écologique: un paradigme pour la réforme environnementale», en Falque. M., Massenet. M., Droits et propriété et environnement, Paris, Dalloz, 1997.

Solow, R. M., «An almost practical step toward sustainability», en Oates. W.E., The REF Reader in Environmental and Resource Management, Washington D.C., Resources for the Future, 1992.

THÉRY, J., «Plaidoyer pour Développer des technologies plus appropriées et passer du mimétisme au pluralisme technologique», Revue tiers-monde, vol. 22, núm. 88, 1981.

Vivien, F.-D. y Zuindeau, B., «Le développement durable et son espace: antécédents intellectuels et questions pour l'avenir», Cahiers lillois d'économie et de sociologie, núm. 37, 2001.

Zuindeau, B., Développement durable et territoire, Villeneuve-d'Ascq, Presses Universitaires du Septentrion, 2000. 